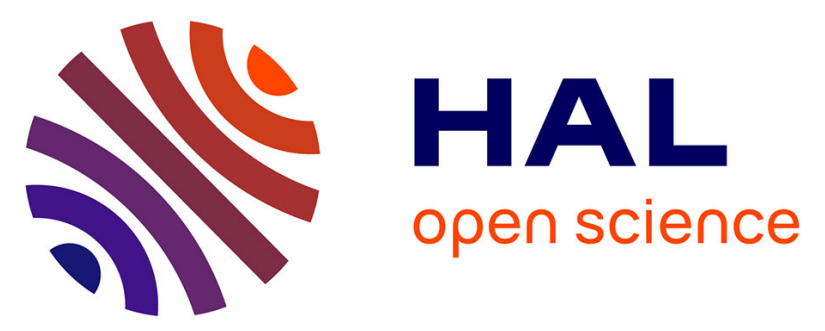

\title{
A novel operando approach to analyze the structural evolution of metallic materials during friction with application of synchrotron radiation
}

\author{
I.A. Bataev, D.V. Lazurenko, A.A. Bataev, V.G. Burov, I.V. Ivanov, K.I. \\ Emurlaev, A.I. Smirnov, M. Rosenthal, M. Burghammer, D.A. Ivanov, et al.
}

\section{To cite this version:}

I.A. Bataev, D.V. Lazurenko, A.A. Bataev, V.G. Burov, I.V. Ivanov, et al.. A novel operando approach to analyze the structural evolution of metallic materials during friction with application of synchrotron radiation. Acta Materialia, 2020, 196, pp.355-369. 10.1016/j.actamat.2020.06.049 . hal-03095912

\section{HAL Id: hal-03095912 https://hal.science/hal-03095912}

Submitted on 4 Jan 2021

HAL is a multi-disciplinary open access archive for the deposit and dissemination of scientific research documents, whether they are published or not. The documents may come from teaching and research institutions in France or abroad, or from public or private research centers.
L'archive ouverte pluridisciplinaire HAL, est destinée au dépôt et à la diffusion de documents scientifiques de niveau recherche, publiés ou non, émanant des établissements d'enseignement et de recherche français ou étrangers, des laboratoires publics ou privés. 


\section{Journal Pre-proof}

A novel operando approach to analyze the structural evolution of metallic materials during friction with application of synchrotron radiation

I.A. Bataev , D.V. Lazurenko, A.A. Bataev, V.G. Burov , I.V. Ivanov, K.I. Emurlaev, A.I. Smirnov, M. Rosenthal, M. Burghammer, D.A. Ivanov, K. Georgarakis , A.A. Ruktuev , T.S. Ogneva , A.M.J. Jorge

PII: S1359-6454(20)30484-5

DOI: https://doi.org/10.1016/j.actamat.2020.06.049

Reference: AM 16126

To appear in:

Acta Materialia

Received date:

28 March 2020

Revised date:

16 June 2020

Accepted date:

23 June 2020

Please cite this article as: I.A. Bataev, D.V. Lazurenko, A.A. Bataev, V.G. Burov, I.V. Ivanov , K.I. Emurlaev, A.I. Smirnov, M. Rosenthal, M. Burghammer, D.A. Ivanov, K. Georgarakis, A.A. Ruktuev, T.S. Ogneva, A.M.J. Jorge, A novel operando approach to analyze the structural evolution of metallic materials during friction with application of synchrotron radiation, Acta Materialia (2020), doi: https://doi.org/10.1016/j.actamat.2020.06.049

This is a PDF file of an article that has undergone enhancements after acceptance, such as the addition of a cover page and metadata, and formatting for readability, but it is not yet the definitive version of record. This version will undergo additional copyediting, typesetting and review before it is published in its final form, but we are providing this version to give early visibility of the article. Please note that, during the production process, errors may be discovered which could affect the content, and all legal disclaimers that apply to the journal pertain.

(C) 2020 Published by Elsevier Ltd on behalf of Acta Materialia Inc. 


\section{A novel operando approach to analyze the structural evolution of metallic materials during friction with application of synchrotron radiation}

I.A. Bataev ${ }^{1 *}$, D.V. Lazurenko ${ }^{1}$, A.A. Bataev ${ }^{1}$, V.G. Burov ${ }^{1}$, I.V. Ivanov ${ }^{1}$, K.I. Emurlaev $^{1}$, A.I. Smirnov ${ }^{1}$, M. Rosenthal ${ }^{2}$, M. Burghammer ${ }^{2}$, D.A. Ivanov ${ }^{3,4,5}$, K. Georgarakis ${ }^{6}$, A.A. Ruktuev ${ }^{1}$, T.S. Ogneva ${ }^{1}$, A.M.J. Jorge ${ }^{7,8}$

${ }^{1}$ Novosibirsk State Technical University, 630073, Novosibirsk, Russian Federation

${ }^{2}$ The European Synchrotron, ESRF, CS40220, F-38043 Grenoble Cedex 9, France

${ }^{3}$ Lomonosov Moscow State University, Leninskie gory 1, 119991, Moscow, Russian Federation

${ }^{4}$ Institute of Problems of Chemical Physics, Russian Academy of Sciences, Chernogolovka 142432,

Russian Federation

${ }^{5}$ Institut de Sciences des Matériaux de Mulhouse-IS2M, CNRS UMR 7361, Jean Starcky, 15, F68057, Mulhouse, France

${ }^{6}$ School of Aerospace, Transport and Manufacturing, Cranfield University, Cranfield, MK43 0AL, UK

${ }^{7}$ Federal University of Sao Carlos, Via Washington Luiz, Km 235, 13565-905 Sao Carlos, SP, Brazil

${ }^{8}$ LEPMI and SIMAP Laboratories, CNRS UMR 5266, Grenoble Alpes University, Institut Polytechnique, BP. 75, St-Martin d'Heres 38402, France

"Corresponding author information:

E-mail: ivanbataev@ngs.ru

Phone: +79139132956

Fax: +73833460612

Postal address: Novosibirsk State Technical University, 630073, Novosibirsk, Russian Federation

\section{ABSTRACT}

In this study, we describe an experimental setup and a new approach for operando investigation of structural evolution of materials during wear and friction. The setup is particularly suited for testing various friction pairs, including those in which both rubbing bodies are made of metals. The developed device allows circumventing the problems related to significant scattering of Xrays produced by metals and makes it possible using "real samples" in synchrotron beamlines operating in reflection mode. To demonstrate the capabilities of the device and the proposed new approach, an iron-based massive sample was subjected to thousands of friction cycles using a cemented carbide pin. The material was probed with synchrotron X-ray radiation within a few milliseconds after leaving the friction zone. The results of the microstructural and structural analysis, as well as results obtained from diverse mathematical models, allowed us to evaluate several features, including gradual accumulation of defects, microstructural refinement, dislocation density changes, surface layer oxidation, as well as several other phenomena caused by the dry sliding friction process. Mainly, it was possible to conclude that the process of wear occurred due to the cooperative action of oxidation and plastic deformation, which began during the first cycle of frictional interaction and was manifested in increasing the dislocation density, whose type was changed gradually during testing. The number of defects quickly reached a threshold value and subsequently fluctuated around it due to periodically repeated processes of defect accumulation and stress relaxation resulting from material wear. It was also observed that friction led to the quick formation of a mechanically mixed layer, consisting of the sample material and a mixture of two types of iron oxide - hematite and magnetite. The delamination of this layer was probably the primary wear mechanism.

Keywords: wear, subsurface layer, structural evolution, synchrotron, in-situ, operando 
Table of content

1. Introduction 2

2. Description of experiment and characterization techniques .................................................

2.1. Friction tester for simultaneous synchrotron analysis of the samples' surface .......................... 4

2.2. Experimental materials, testing regimes, and materials characterization techniques................... 6

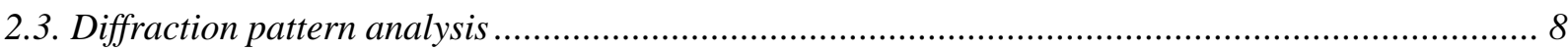

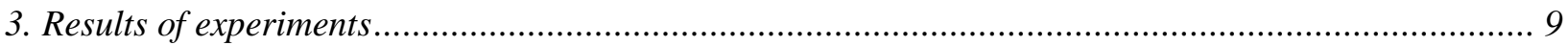

3.1. Analysis of peak broadening and defect accumulation analysis in operando mode ..................... 9

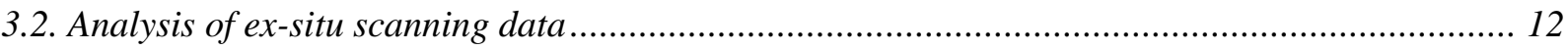

3.3. Synchrotron analyses of tribo-oxidation process .................................................... 14

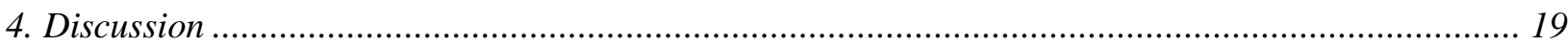

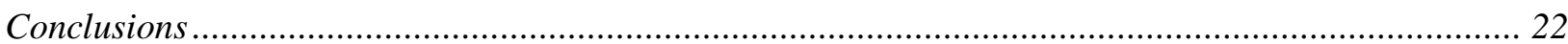

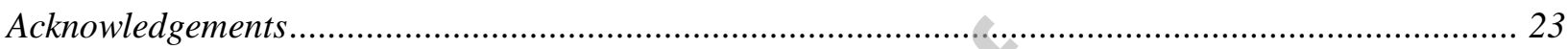

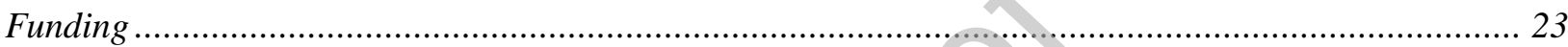

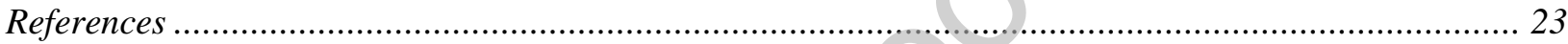

\section{Introduction}

The phenomenon of friction and the accompanying wear have always been of particular interest to science and engineering. The total costs of energy required to overcome friction by different machines and mechanisms, make up from 2 to $6 \%$ of the GDP of economically developed countries $[1,2]$. Equipment operating under friction conditions in most cases fails due to wear [3]. Such observation is especially true when operating conditions are associated with dry sliding friction, but this problem may also happen in cases of rolling friction. The problem is worth mentioning if one takes into account that dry sliding friction is an inevitable and even desirable phenomenon in some products, for example, in braking systems.

In terms of wear rate, dry sliding friction is one of the most "severe" processes. It is associated with several wear mechanisms, including but not limited to, adhesive, fatigue, abrasive, and corrosion wear [4-6]. The prevalence of a specific wear mechanism depends primarily on the parameters of the friction process, as well as on its stage.

However, in real situations, multiple friction mechanisms usually act simultaneously [7, 8]. Numerous metallographic studies of materials subjected to dry sliding friction reveal severe plastic deformation occurring in the subsurface layers of rubbing bodies [9-13]. Besides, one may observe the occurrence of chemical reactions between the environment and materials of the friction pair, the mechanical mixing of these materials, and the formation of thin near-surface layers, the properties of which differ sharply from that of internal volumes of the samples. These layers are termed differently in the literature [14-16], for instance, mechanically mixed layers (MML), transfer layers, tribological layers, fragmented layers, highly deformed layers, glaze layers, white-etching layers, nanocrystalline layers, third body, etc. The material under these layers also undergoes significant changes, leading to the formation of the so-called subsurface layer [17]. The structure and properties of such subsurface layers gradually or abruptly approach to those of the base metal as the distance from the surface increases.

Most studies indicate that, regardless of friction process conditions, the structure of subsurface layers changes very fast and transforms into a new state, which, as a rule, differs significantly from the initial state in its mechanical and chemical properties [8, 18]. The structural evolution of surface layers during friction is extraordinarily complex. Its thorough 
understanding allows conscious decision taking on selection of tribological materials as well as on technologies for their bulk and surface processing, providing high reliability and durability of the friction pair.

A significant number of studies have been devoted to the processes of structural evolution during friction. It is challenging to cover all of them within the scope of a single paper. With the advent of the first methods of X-ray and electron diffraction analysis in the early twentieth century, it was found that, under friction, the structure of the surface layers undergoes substantial refinement and, in some cases, amorphization. The layer formed in such cases is sometimes called the Beilby layer [19].

Long-term frictional impact on carbon steels also leads to the formation of nanocrystalline layers, which, under certain conditions, have white color (so-called white etching layers or WEL) [20-24]. The formation of a nanocrystalline structure during friction occurs due to the deformation and accompanying heating of the material in the contact area, as well as due to subsequent rapid heat transfer into the inner layers of the metal.

The principle mechanisms of structural evolution and surface nanostructuring during friction were studied in detail using experimental and theoretical approaches (e.g., Panin et al. [9]). Here it was suggested that structural changes during friction arise in a similar way as during other types of plastic deformation. Thus, the friction is accompanied by the following phenomena: generation of dislocations, formation of small-angle boundaries due to rearrangement of dislocations into dislocation walls, appearance of disclination dipoles, and formation of fragments. Subsequent plastic deformation occurs due to the movement of the entire fragmented layer along the friction surface. The plastic deformation of subsurface layers leads to their strong texturing. As a rule, the planes of easy slip are oriented parallel to the friction surface [25-27].

Although the transition of the structure to some steady state under conditions of dry sliding friction is extraordinarily rapid, this process is not instantaneous. It comprises several stages of accumulation of defects in the crystal structure [17]. During each cycle of frictional loading, the strain accumulated in the material increases by a small amount. Upon reaching a certain limit, the surface layer fails, forming wear debris [14].

Most of the studies devoted to the analysis of materials' structure formed during friction are based on results of ex-situ studies performed using light or electron microscopy. One of the main disadvantages of these methods is the necessity to interrupt an experiment after a particular time and prepare the specimen for analysis. Firstly, such an approach allows obtaining only data on structural changes occurring in a specific moment of the frictional process. Secondly, the sample preparation procedure, which often involves various mechanical operations, may lead to structural changes other than those caused by the friction, indirectly affecting subsequent conclusions. Thirdly, sample preparation is destructive, hence not allowing for tracking further structural evolution of the same sample during ongoing testing.

Significant progress in understanding the structural evolution during friction was achieved due to the application of various in situ methods, which allowed evaluating structural changes occurring directly in the friction zone. In recent decades, new highly sensitive in-situ tribometers have been developed providing a high-frequency estimation of the friction coefficient and images of the contact zone [28-30], and, in some cases, information on chemical bonds using Raman spectroscopy [31, 32]. Transparent pins and infrared cameras provide information about the temperature of the contact zone directly in the process of friction [33, 34]. In recent years, a better understanding of microcutting mechanisms (formation of tribolayers, wear debris, the evolution of the dislocation structure) during friction was achieved due to in situ 
tribometers installed in scanning electron microscopes (SEM) and transmission electron microscopes (TEM) [35-40].

Particularly noteworthy are methods based on in situ and operando X-ray diffraction (XRD) analysis [41, 42]. The modern high-intensity synchrotron radiation sources enable to study phenomena occurring directly in the area of frictional interaction or close to it. Kajita et al. [43] and Yagi et al. [44] used an apparatus with a single-crystal sapphire disk rubbing against a pin-shaped sample made of steel. The use of a sapphire disk (crystallographically oriented to be transparent to the light in the range from the visible to the near-infrared wavelengths, and having low interaction with X-rays) allowed them to record the processes of the wear debris generation, plastic deformation, heating, and phase transformations occurring under conditions of severe wear of steel.

The application of in-situ technique described by Kajita et al. and Yagi et al. [43, 44] to real friction pairs, in which both rubbing bodies are made of metal alloys, is limited since the metals significantly scatter X-rays and can be transmitted only when the samples are relatively thin. Due to these reasons, microscopic and diffraction analyses of the material located in the contact zone of bulky metallic samples, frequently used in real friction pairs, are non-trivial tasks. To address these issues, a new experimental device was developed, allowing to investigate the structural evolution of materials in-operando. A bulk material subjected to friction was probed within a few milliseconds after leaving the friction zone. Using a "cemented carbide steel" friction pair, we demonstrate the capabilities of this novel approach, which allowed us to observe several stages of defects accumulation, microstructural refinement, dislocation density changes, surface layer oxidation, as well as several other phenomena caused by the dry sliding friction process.

\section{Description of experiment and characterization techniques}

\subsection{Friction tester for simultaneous synchrotron analysis of the samples' surface}

A simplified schematic of the experimental geometry used in this study is shown in Fig. 1. The test sample - a disk with a diameter of $66 \mathrm{~mm}$ - was loaded with a pin-shaped counterbody pressing against the cylindrical surface. A monochromatic and X-ray micro-beam probes the cylindrical surface of the sample at a small distance from the pin. Thus, the material that recently left the friction contact zone is analyzed. This scheme allows observing the structural changes that occurred in a given region of the sample during each cycle of frictional loading in operando. The two-dimensional diffraction patterns are then recorded using a 2D-pixel detector mounted downstream of the sample.

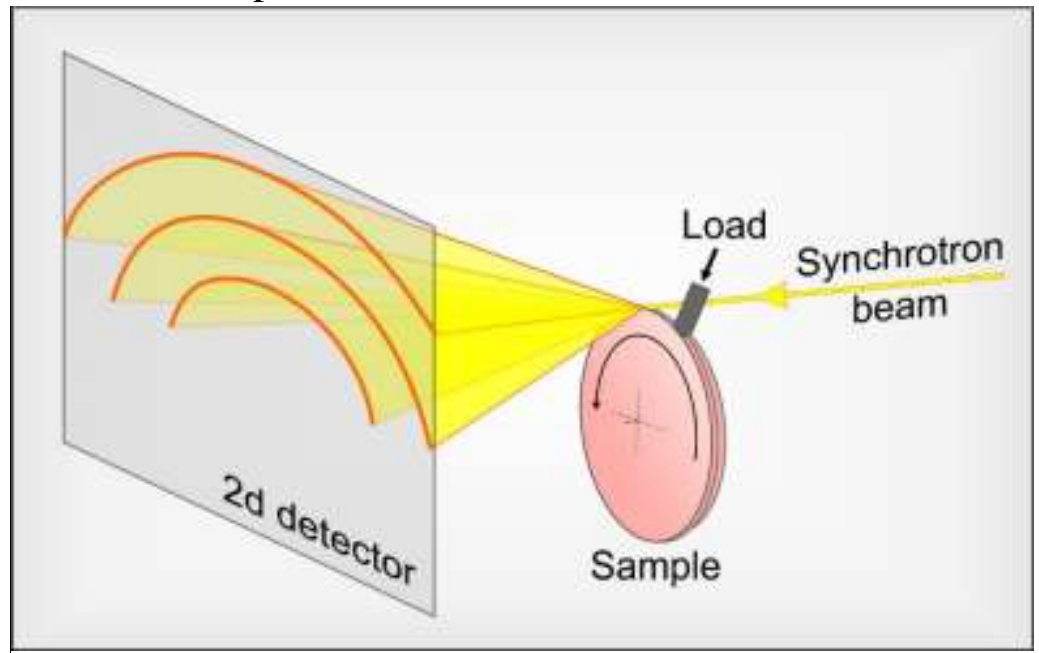

Fig. 1. Schematic diagram of the setup used in the experiments (not to scale). 
The friction tester designed to implement this experimental approach is shown in Fig. 2. The sample is centered on a spindle by means of an expanding collet and fixed with bolts. A servo motor drives the spindle through a gear belt drive that provides high torque and an adjustable sample rotation speed in the range from 0.6 to $300 \mathrm{rpm}$. All these parts are rigidly fixed on an aluminum frame, which could move vertically along two linear guide rails within the device housing. Using a lever mechanism connected to a loaded basket, the fixed test sample is pressed against the rigidly fixed pin. The load was controlled by adjusting the weight in the basket. The pin is made of a hard material, the wear of which during the experiment being insignificant. Before starting the experiment, the device was positioned in such a way that the probing point of the focused X-ray beam was in the middle of the cylindrical surface of the sample at a predetermined distance from the pin. Due to the wear, the sample diameter was continuously decreased. The design decision to mount the pin statically while the sample constantly exerts the force against it via the lever mechanisms was chosen to allow the system to account for the wear induced decrease of the sample diameter. Thus, the focal spot of the X-ray beam stays on the center of the cylindrical surface, and the sample-to-detector distance remains virtually constant during the experiment. The device provides a load of up to $500 \mathrm{~N}$. Thus, considering the geometry of the sample and the pin, the maximum pressure in the friction zone can reach up to $500 \mathrm{MPa}$. Although the device was used to analyze the process of dry sliding friction in this study, its design allows using a variety of lubricants.

The shape of the pin is shown in Fig. 2. The width of the contact surface is $1 \mathrm{~mm}$. In the described experiment, the pin is made of a WC-Co cemented carbide alloy (80\% WC and $20 \%$ Co).

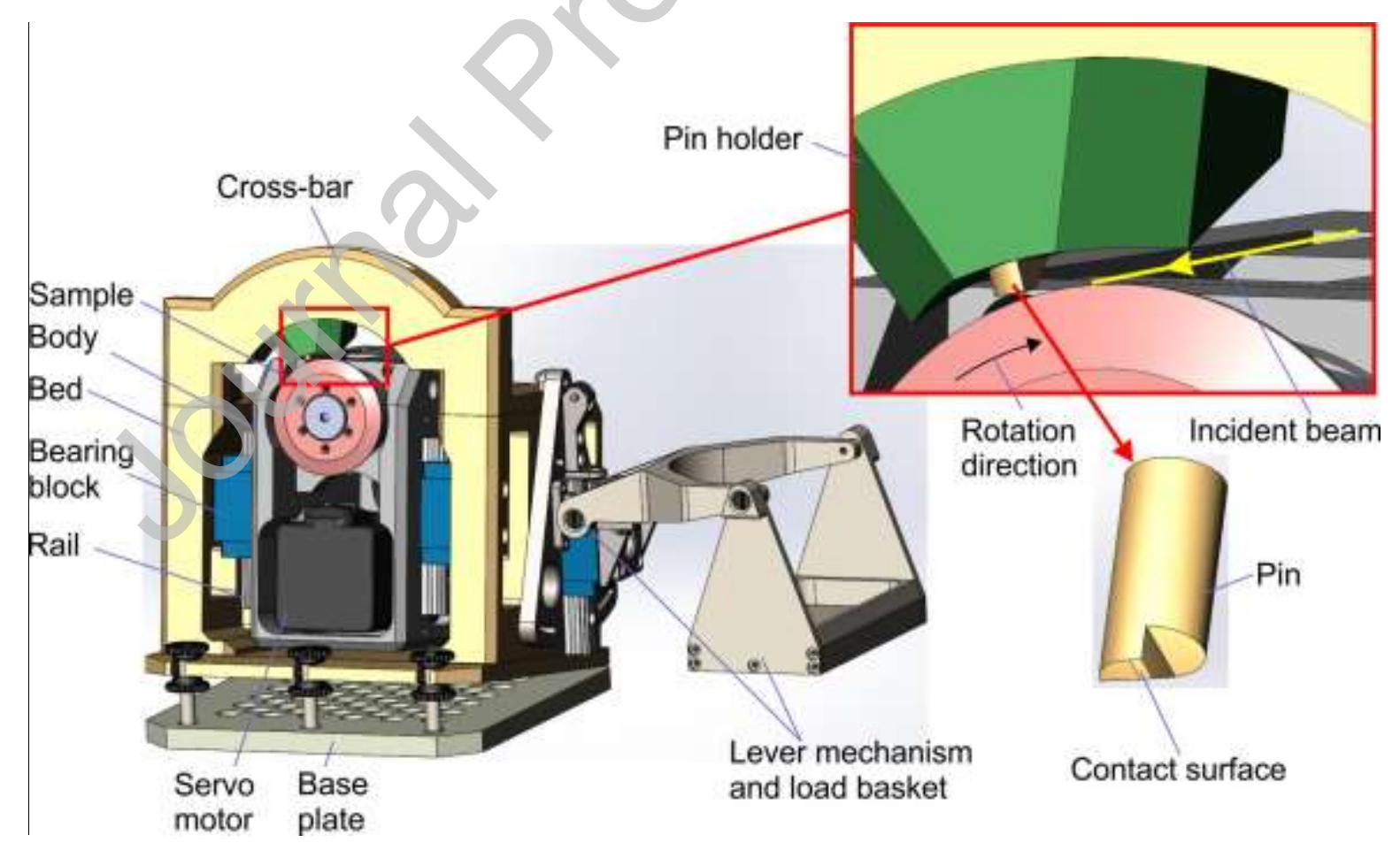

Fig. 2. 3D-model of the friction tester providing simultaneous control of surface structure using synchrotron X-ray diffraction.

The friction tester was installed at the beamline ID13 (Microfocus beamline) of the European synchrotron radiation facility (ESRF) (Fig. 3.). The optical system of the beamline provides a high-intensity X-ray beam focused to a spot of a few micrometers in size. In the 
current study, the cross-section of the beam in terms of the full width at half maximum (FWHM) was $2.8(\mathrm{H}) \times 1.3(\mathrm{~V}) \mu \mathrm{m}^{2}$. The grazing angle of the beam with respect to the rotation axis was chosen to be equal to $\alpha=3.6^{\circ}$. Thus, the footprint of the beam onto the cylindrical sample surface was $2.8 \times 21 \mu \mathrm{m}^{2}(\mathrm{H} \times \mathrm{V}$, where $\mathrm{H}$ and $\mathrm{V}$ stand for horizontal and vertical dimensions, respectively). The photon energy of the X-ray beam was set to $13.9 \mathrm{keV}$, corresponding to the wavelength of $0.8919726 \AA$. The whole experimental device was mounted on a precision XYZ gantry to position the sample with respect to the synchrotron beam. The X-ray diffraction (XRD) patterns were recorded using the 2D detector (Dectris Eiger 4M), which has a spatial resolution of $2070 \times 2167$ pixels and the highest possible recording rate of 750 frames per second with a dead time of $10 \mu \mathrm{s}$. The physical size of the active detector area is $155.2 \times 162.5 \mathrm{~mm}^{2}$ with a pixel size of $75 \times 75 \mu \mathrm{m}^{2}$. The sample-to-detector distance was set to $95 \mathrm{~mm}$.

The thickness of the layer analyzed in the experiments can be estimated using the law of X-ray intensity attenuation due to its interaction with the material. According to this law, the attenuation occurs mainly due to the various quantum effects (e.g., photoabsorption, Compton scattering) and obeys the expression [45, 46]:

$$
I(x)=I_{o} e^{-\mu x}
$$

where $I_{o}$ is the initial intensity of the incident beam, and $\mu$ is the linear absorption coefficient. Knowing that the value of $\mu$ for iron at an X-ray energy of $13.9 \mathrm{keV}$ is $553.5 \mathrm{~cm}^{-1}$ [47], it can be estimated that the effective penetration depth of the beam (i.e., the depth at which the initial intensity decreases by $e$ times) is $\mathrm{x}_{\mathrm{eff}}=18 \mu \mathrm{m}$. Also, the depth at which the beam weakens by $95 \%$ regarding the initial intensity is $\mathrm{x}_{0.95}=54 \mu \mathrm{m}$. Considering the grazing angle $\alpha$, one can roughly estimate the thickness $t$ of the analyzed layer by substituting $x$ to the equation $t=$ $0.5 x \sin \alpha$, which results in $t_{\text {eff }}=0.57 \mu \mathrm{m}$ and $t_{0.95}=1.7 \mu \mathrm{m}$. In other words, in the current study, the thickness of the analyzed material did not exceed a few micrometers.
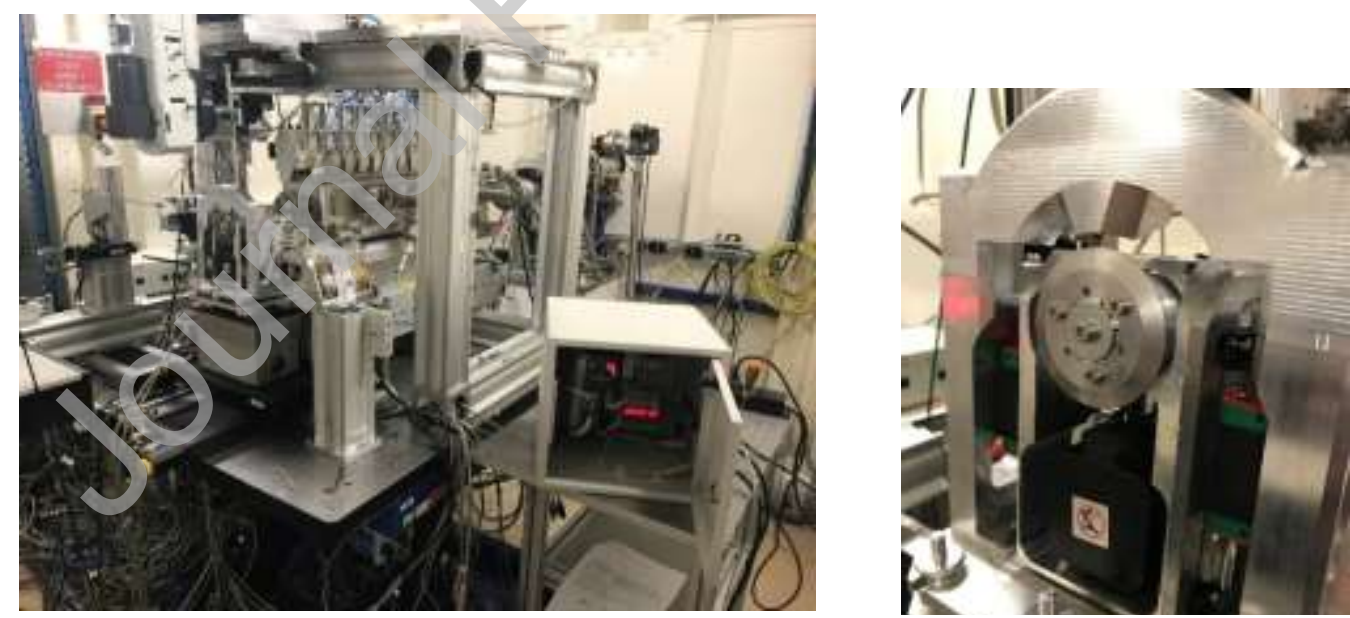

Fig. 3. The friction tester installed at the ID13 beamline of ESRF.

\subsection{Experimental materials, testing regimes, and materials characterization techniques}

A medium carbon steel of the following composition was used to prepare experimental samples: 0.45 wt. \% C, 0.8 wt. \% Mn, 0.25 wt. \% Si, other impurities less than 0.5 wt. \%. This alloy is frequently used as the basis for many engineering alloys and is widely used in friction devices, making it a convenient choice for testing a new methodology. The samples were prepared from a round bar by lathing and subsequent grinding of the surface. The final polishing was done using a diamond paste with a grain size of $1 \mu \mathrm{m}$. After the final polishing, the sample was annealed in a vacuum furnace at $850{ }^{\circ} \mathrm{C}$ and below $1.3 \mathrm{mPa}$ for 1 hour to reduce defects introduced during the machining process. It is noteworthy that, despite the use of a vacuum 
furnace, a thin light-yellow film was visible on the sample surface after the heat treatment. Due to the high chemical affinity between iron and oxygen, one may infer that this film was an iron oxide. This assumption was subsequently confirmed by diffraction analysis. According to [48], the approximate thickness of the iron oxide film having such a color was about $45 \mathrm{~nm}$.

The selection of the friction conditions was based on two main criteria. The first one was to provide a load at which the accumulation of deformation occurred gradually without instant damage of the surface during the first friction cycles. The final experimental regimes were selected so that the significant damage could be observed only after several hundreds of sample's revolutions. The second criterion was to avoid excessive heating of the material, which could affect the structural state of the wearing sample. Due to these reasons, for the in-operando experiment, a load of $100 \mathrm{~N}$ and a rotation speed of $60 \mathrm{rpm}$ (providing at the cylindrical surface a linear velocity of $0.22 \mathrm{~m} / \mathrm{s}$ ) were selected. Considering the small size of the pin tip and the comparably large diameter of the sample, the contact area between the sample and the pin can be estimated under the assumption that the interacting surfaces were flat. For all the samples used in the described experiments, the contact area is estimated to $\sim 1.5 \mathrm{~mm}^{2}$, which corresponds to a pressure of $67 \mathrm{MPa}$, considering a load of $100 \mathrm{~N}$.

The point, which was probed by the synchrotron beam, was at a distance of $3 \mathrm{~mm}$ from the pin. Thus, the material was analyzed $15 \mathrm{~ms}$ after it left the friction zone. The exposure time of one frame during the measurements was $5 \mathrm{~ms}$. During this time, the linear displacement of the point located on the sample surface was $1 \mathrm{~mm}$. Thus, the diffraction pattern, recorded during one measurement contained information from a $1 \mathrm{~mm}$ long track on the sample's surface. Ten diffraction patterns were recorded during one revolution of the sample to increase the statistical significance of the experiment. This mode of the investigation is referred to in this study as inoperando.

An alternative investigation approach applied in this study takes an advantage of the high throughput continuous scanning capability of the beamline, referred to as the ex-situ approach in this manuscript from here on out. At chosen rotation intervals (after the 1st, 6th, 26th, and 126th revolution), the friction experiment was interrupted, and two-dimensional diffraction scans were performed on the non-rotating sample as schematically illustrated in Fig. 4. The scanning area was $2(\mathrm{H}) \times 0.1(\mathrm{~V}) \mathrm{mm}^{2}$, which corresponded to $410(\mathrm{H}) \times 77(\mathrm{~V})=31570$ diffraction patterns. Scanning of the surface was also carried out before the start of testing ( 0 cycles of friction) and at the end of the test (1126 cycles of friction).

After 1126 revolutions, the total loss in the diameter of the sample was $165 \mu \mathrm{m}$, which corresponded to the mass loss of $198 \mathrm{mg}$. The wear debris generation started after approximately 30 revolutions. Subsequently, debris was continuously generated and collected on a paper placed under the sample.

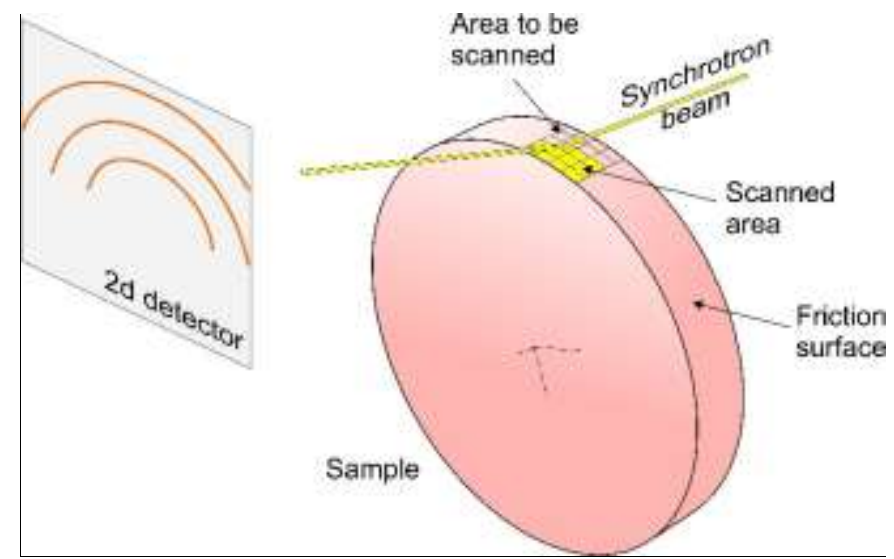

Fig. 4. Scheme of measurements in the ex-situ scanning mode (not to scale). 
Metallographic studies of the samples were carried out using a Carl Zeiss EVO 50 XVP scanning electron microscope coupled with an Oxford Instruments X-Act spectrometer for X-ray energy-dispersive spectroscopy (EDX).

Phase analysis of the wear debris was performed using an ARL X'TRA diffractometer in $\mathrm{Cu} \mathrm{k}_{\alpha 1,2}$ radiation, $2 \theta$ from 30 to 110 degrees, step angle of 0.02 degrees, and a dwell time of 10 seconds per point.

The microhardness distribution in depth from the friction surface was evaluated using a Wolpert Group 402 MVD microhardness tester using a diamond indenter with a load of $0.098 \mathrm{~N}$ and dwell time of $10 \mathrm{~s}$ per point. The measurements were carried out using nonetched polished cross-sections of the samples. The distance from the friction surface to each imprint was carefully measured using an optical microscope. Each value of the microhardness in this manuscript represents the average of 10 measurements. The confidence intervals were calculated for the significance level of 0.05 .

The surface topography of the samples was investigated using a Zygo NewView 7300 optical interferometer.

\subsection{Diffraction pattern analysis}

Two-dimensional diffraction patterns were azimuthally integrated using the PyFAI package developed for the Python programming language [49]. The one-dimensional diffraction patterns obtained by integration were analyzed using the same approaches that are used for XRD patterns acquired with conventional diffractometers with Bragg-Brentano geometry equipped with a point detector.

The FWHM value of the peaks was used in this study as one of the main parameters to evaluate the structural transformations of the material that occur during friction. Due to this reason, the diffraction peak profiles were fitted using the pseudo-Voigt function, which contains FWHM as one of its arguments.

According to the classical study of Williamson and Hall [50], the FWHM of diffracted peaks increases due to two main reasons, namely, due to inhomogeneous microstrains and the size of particles (hereinafter referred to as the size of coherent scattering region (CSR)). The procedure for the deconvolution of the effects of strain and CSR was described in [50] for elastically isotropic materials. The case of elastic-anisotropic materials like $\alpha$-iron was considered in detail in the studies of Ungar et al. [51, 52]. They proposed methods for analyzing the dislocation structure influence on FWHM of diffraction peaks, which are typically referred to as the modified Williamson-Hall (MWH) method and the modified Warren-Averbach (MWA) method. These methods have been successfully tested for different materials, including ironbased alloys like cold-rolled iron [53], high-alloy cold-rolled steel [54], cold drawn pearlitic steel [55] and cold rolled medium carbon steel S45C [56]. The latter one is the Japanese analog of the steel used in this study. Thus, the approaches proposed by Ungar et al. [51, 52] were used in this study to evaluate such microstructural features as the size of CSR, dislocation density, dislocation type (edge or screw), etc.

Since the total number of diffraction patterns obtained during the experiments was about 200000, their analysis was carried out using custom noninteractive batch processing algorithms developed in Python. 


\section{Results of experiments}

\subsection{Analysis of peak broadening and defect accumulation analysis in operando mode}

In this section, the results of the operando mode of investigation are described. I.e., each of the XRD patterns or points in Figs. 5-10 represent a result of a single measurement obtained on a rotating sample.

A set of typical diffraction patterns obtained from the same sample region at various stages of the friction tests is shown in Fig. 5. Since the experiments were carried out in "reflection" geometry, the patterns contain only the upper part of the diffraction pattern, while the lower part of the diffraction cones is absorbed by the sample.
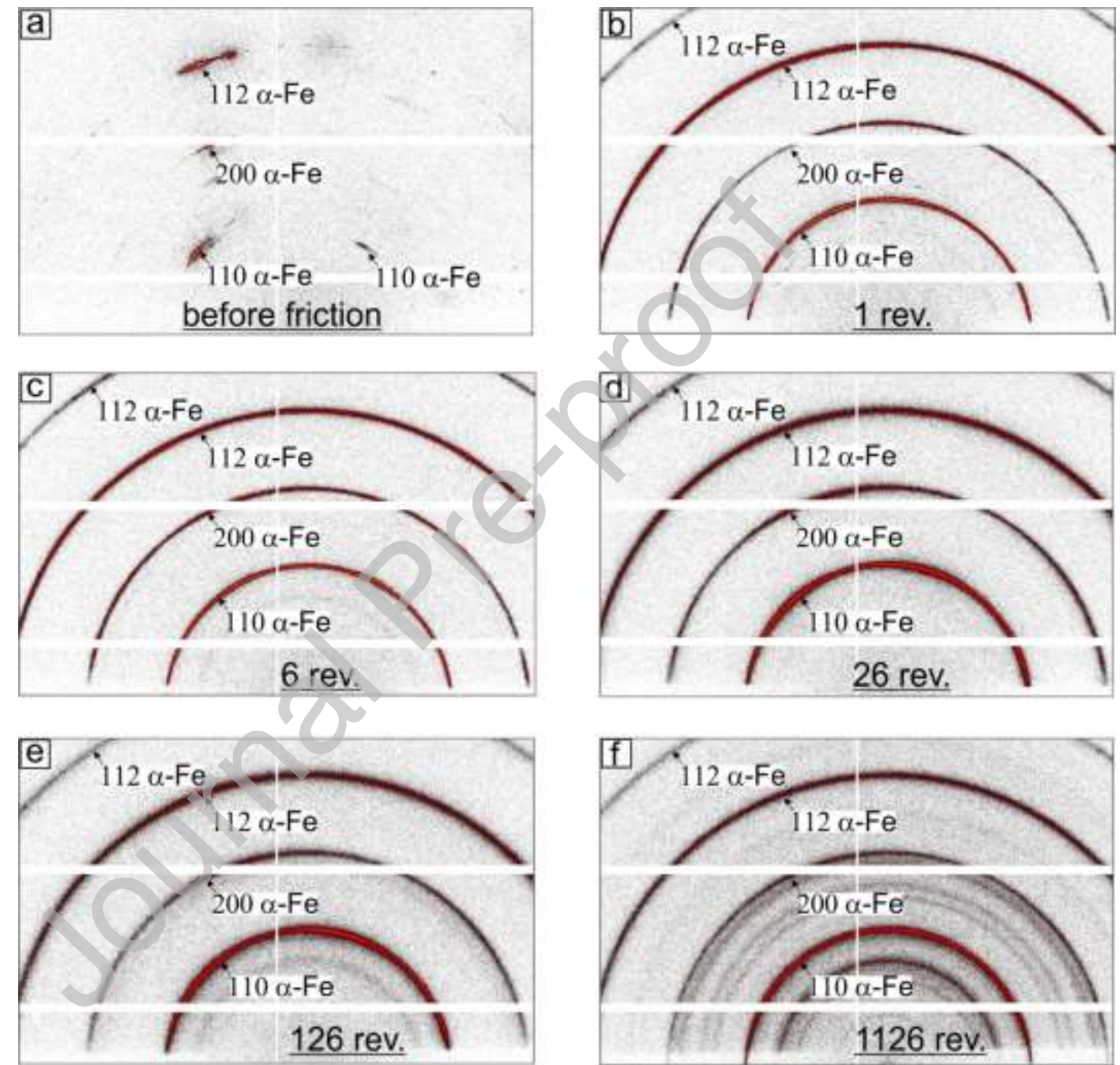

Fig. 5. Two-dimensional XRD patterns recorded after a different number of friction cycles, as indicated in the Figure. The lower part of the diffraction rings was absorbed by the sample. The unmarked diffraction rings belong to iron oxides.

Due to the small beam size, at the initial instant of time, the reflections show only small azimuthal spread indicating a coarse-grained structure of the as-annealed sample (Fig. 5a). However, after the first revolution of the sample, the surface layer of the steel underwent significant changes. In other words, even a small frictional impact led to considerable grain refinement in the surface layer, which was manifested in the formation of an almost continuous powder-like diffraction pattern (Fig. 5b). Also, the weakening of oxide rings was observed. Subsequent frictional impacts led to the broadening of the diffraction rings (Fig. 5c-f). 
Interestingly, oxide rings vanished after the sixth revolution (Fig. 5c) and reappeared after 126 revolutions (Fig. 5e-f). At this time, oxide rings had higher intensity, meaning a strong reoxidation of the sample surface.

The reduced one-dimensional XRD patterns are shown in Fig. 6 as a function of the diffraction angle $2 \theta$. The dominant phase throughout the experiment was $\alpha$-Fe (Fig. 6a). It can be seen that, with an increase in the number of friction cycles, the intensity of the diffraction peaks decreases, while their width increases. Such behavior is a clear indication of the gradual accumulation of defects by the material and microstructural refinement. The peaks' broadening is undoubtedly observed in Figs. $6 \mathrm{~b}$ to $6 \mathrm{c}$. The shift of the peaks, which can also be observed in Figure 6c, will be discussed in Section 3.3.
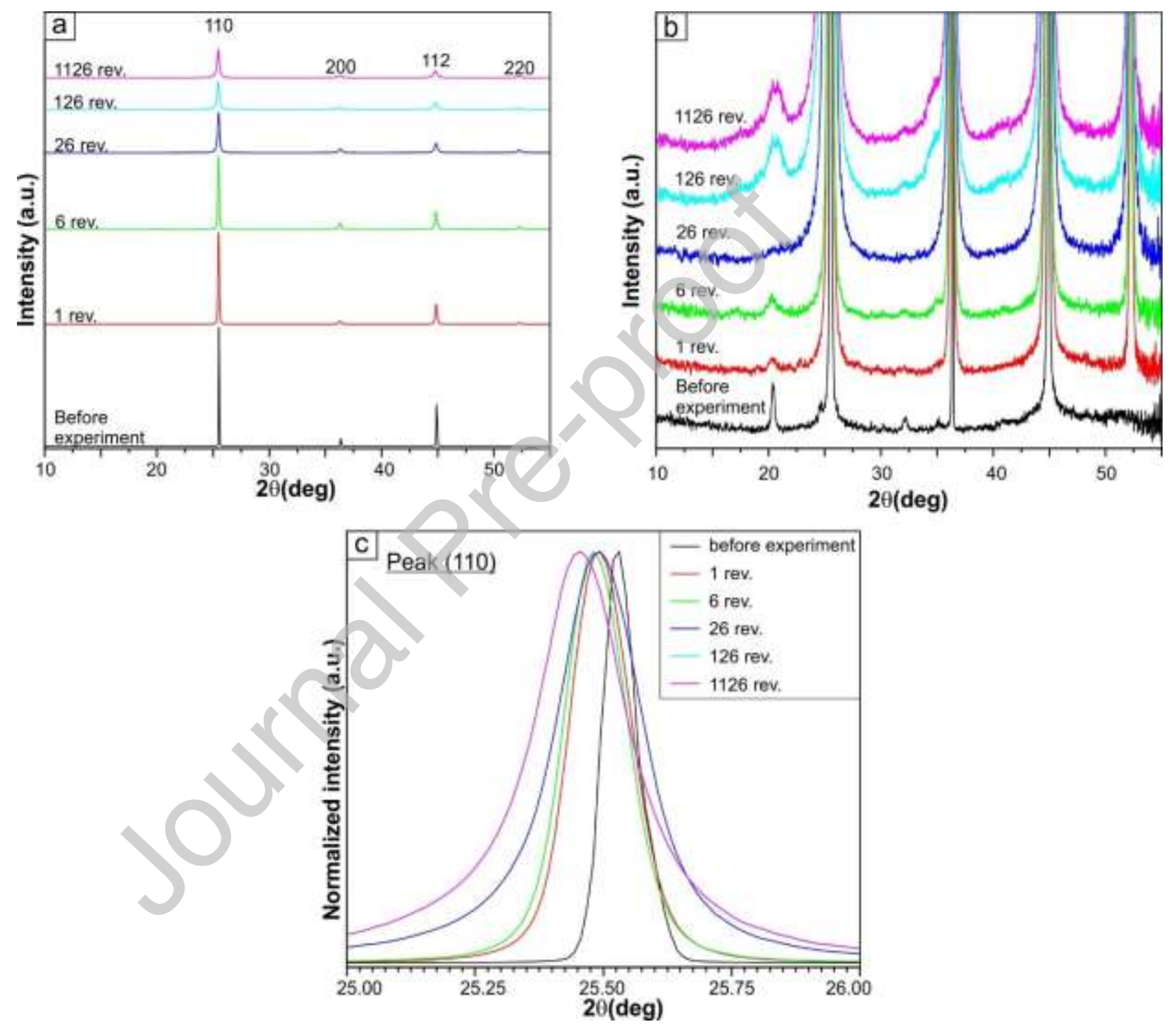

Fig. 6. (a) integrated XRD patterns in coordinates "intensity - 29 " recorded from rotating sample, (b) same as (a) but enlarged, (c) normalized peak (110), which broadened and shifted to lower angles with the number of friction cycles.

The increase of the peak width can be described using the FWHM. The variation of FWHM of the $\alpha$-Fe peaks with the number of revolutions measured on a rotating sample is shown in Fig. 7. The rapid broadening of the peaks due to the intensive accumulation of defects and the microstructural refinement was observed during the first 40 cycles. After that, the FWHM reaches a plateau, and the subsequent growth of this parameter practically ceased. From 
approximately the $200^{\text {th }}$ cycle until the end of the experiment, the data show an oscillation behavior of the FWHM.
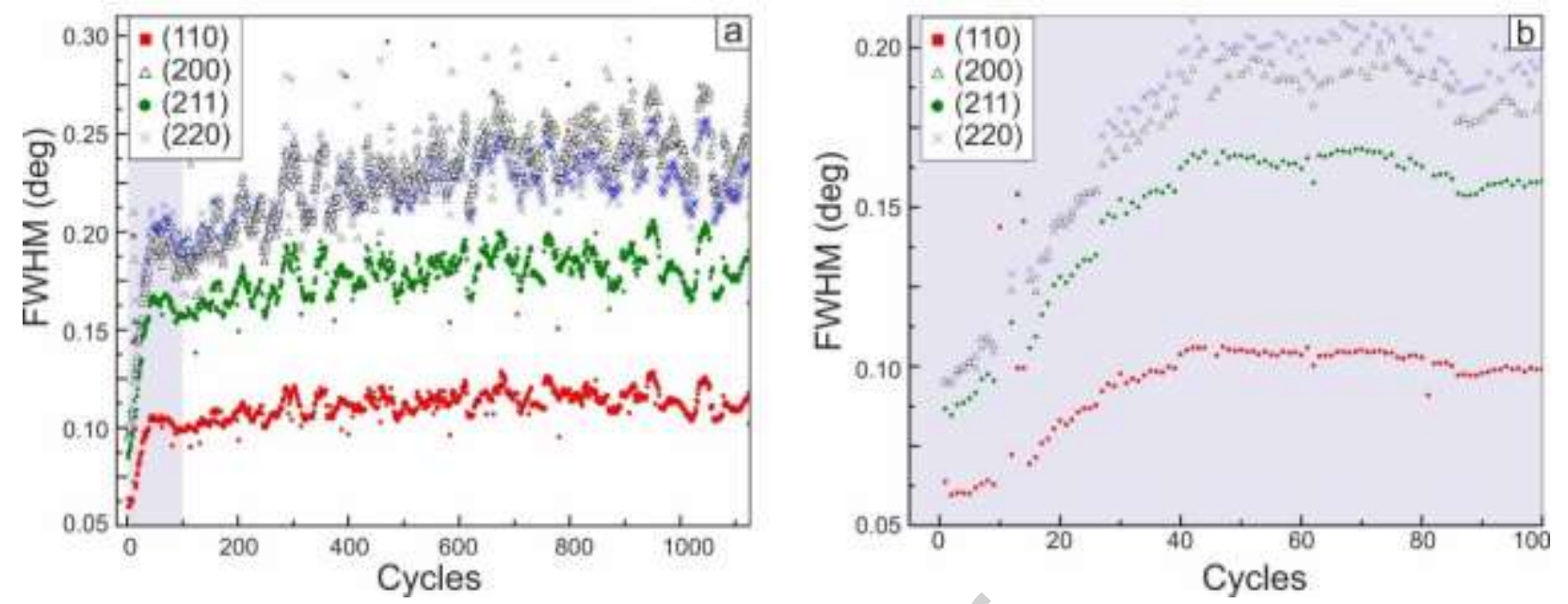

Fig. 7. Relation between the FWHM for peaks of $\alpha$-Fe and number of friction cycles (a). The scatter chart in (b) is an enlarged region, shaded in the scatter chart (a).

The evolution of the CSR size, determined using the MWH method, is presented in Fig. 8. As in the case of FWHM, the CSR size changed sharply during the first 40 cycles, during which this parameter decreased from $\sim 300 \mathrm{~nm}$ to $\sim 65 \mathrm{~nm}$. Further refinement was much slower. The minimum size of the CSR achieved after 1126 cycles of friction was $59 \mathrm{~nm}$. Some fluctuations in the CSR parameter overtime near the achieved value are observed on the chart.

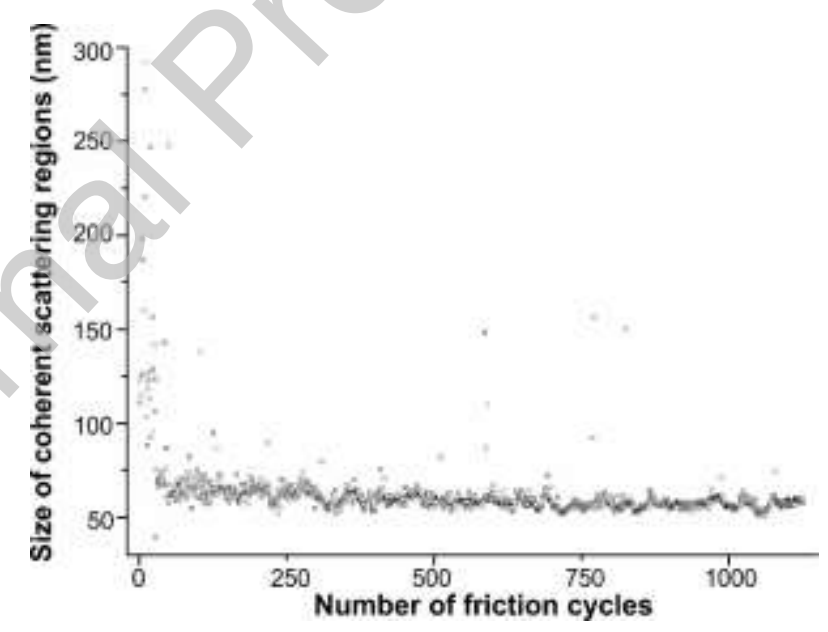

Fig. 8. The relation between CSR size and the friction cycle.

The MWH model of peak broadening contains several essential arguments, which may characterize the structure, including the so-called $\boldsymbol{q}$ parameter (see equations 7,9 , and 12 in the study of Ungar et. al [51]). This parameter depends on the elastic constants of the crystal, and it differs for edge and screw dislocations. Following the procedure described in [51], one may find that the $q$ parameter for screw dislocations in $\alpha$-Fe is 2.5 , while for edge dislocations, it is 1.35 . At the same time, $\boldsymbol{q}$ may be found by fitting the MWH model to experimental data. Thus, the value of $\boldsymbol{q}$ obtained from the experiment allows calculating the edge to screw dislocations ratio. These data are presented in Fig. 9. It can be noted that in the as-annealed sample, the fractions of screw and edge dislocations were approximately the same. During the first tens of friction cycles, there was a slight increase in the fraction of edge dislocations, and then there was a 
gradual increase in the fraction of screw dislocations. At the end of the experiment, more than $90 \%$ of the dislocations in the surface layer were of a screw type.

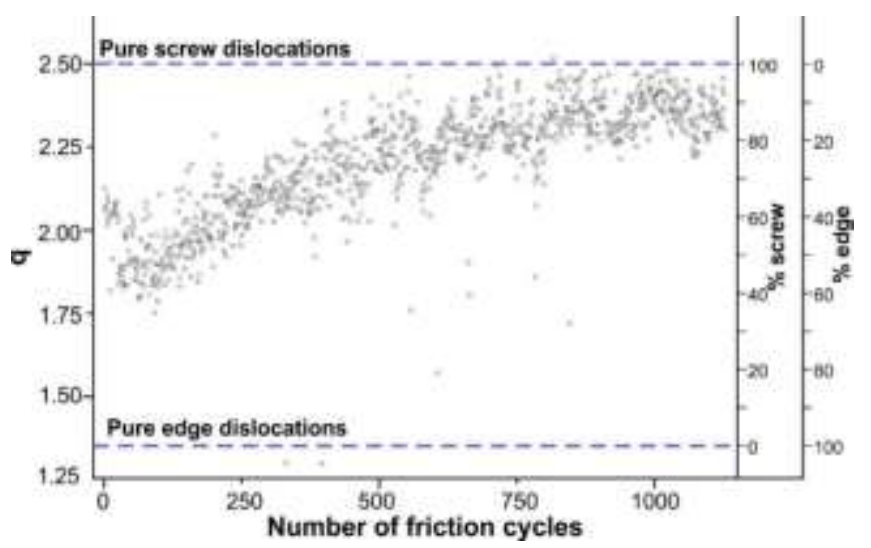

Fig. 9. Variation of a q parameter used in the MWH model to estimate the fractions of screw and edge dislocations in highly deformed materials.

The MWA model allows estimating the change in the dislocation density depending on the friction cycle. From the chart shown in Fig. 10 it follows that the dislocation density, as well as FWHM and the CSR size, significantly changed during the first tens of friction cycles, finally reaching a plateau. The large scatter of the values is probably due to the insufficiently high quality of the diffraction profiles, which, in turn, was associated with the extremely short exposure time in the in-operando mode as well as with the mechanical stability of the setup.

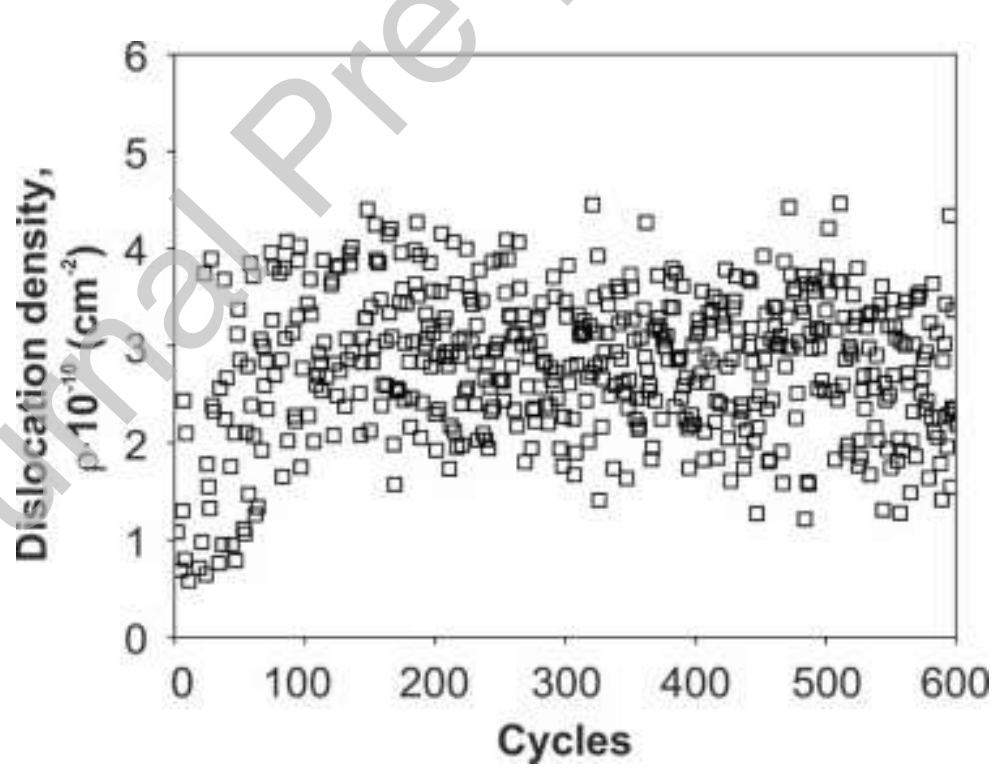

Fig. 10. Variation of the dislocation density with the number of friction cycles.

\subsection{Analysis of ex-situ scanning data}

Diffraction patterns obtained from a few points of the sample do not provide a complete understanding of structural changes caused by friction, especially if one assumes that the structure formed as a result of friction can be very inhomogeneous. Due to a relatively small size of the focused X-ray beam, the scanning across the sample's surface becomes possible, which allows obtaining information about the spatial distribution of microstructural parameters.

As an example, Fig. 11 shows the distributions of intensity (Fig. 11a-f) and FWHM (Fig. 11g-l) of (112) reflections after a different number of friction cycles. For the as-annealed state, the intensity of such reflections was distributed unevenly. The areas of high intensity correspond 
to regions having favorable Bragg's orientation, which was related to the coarse-grained structure of the sample. The friction "track" left by the pin was observed on the sample's surface even after the first revolution (Fig. 11b). Within this track, the distribution of the (112) line intensity became more uniform. However, areas with increased intensity were still discernible. These regions could also be distinguished after six cycles of friction loading (Fig. 11c). However, they were significantly less contrasting, which is demonstrated by the difference between the maximum and minimum intensities within the friction track that was noticeably reduced. This is probably explained by the fact, that during the first revolutions, only a thin layer is subjected to the deformation, while the probing depth is still larger. After 26 friction cycles, there was a significant equalization of the (112) intensity over the entire friction track. However, after a significant number of friction cycles, a pattern that resembles the grooves left by the pin appeared on the sample's surface. It can also be noted that the width of the friction track substantially increased up to the $26^{\text {th }}$ cycle. Thus, this stage was considered as the running-in stage. Subsequent friction cycles did not lead to a significant increase in the width of the friction track since almost the entire surface of the sample was deformed after such amount of cycles.

The deformation and the corresponding accumulation of defects led to the expected broadening of the XRD peaks. For the as-annealed state, the FWHM of the (112) line was almost the same (about $0.05^{\circ}$, Fig. $11 \mathrm{~g}$ ) at different points of the sample. Due to the impact of the pin, XRD peaks gradually broadened. A particularly noticeable broadening was observed after the first tens of test cycles (Fig. 11h-j), at the same time, there was no significant difference between measurements after 126 (Fig. 11k) and 1126 (Fig. 111) friction cycles.

It is noteworthy that, after a considerable number of revolutions (126 or more), a specific line-broadening pattern was formed on the sample's surface. In other words, the formation of alternating bands of high and low intensity along the friction track and periodic variations of broadening along with each band (Fig. 11k,1).

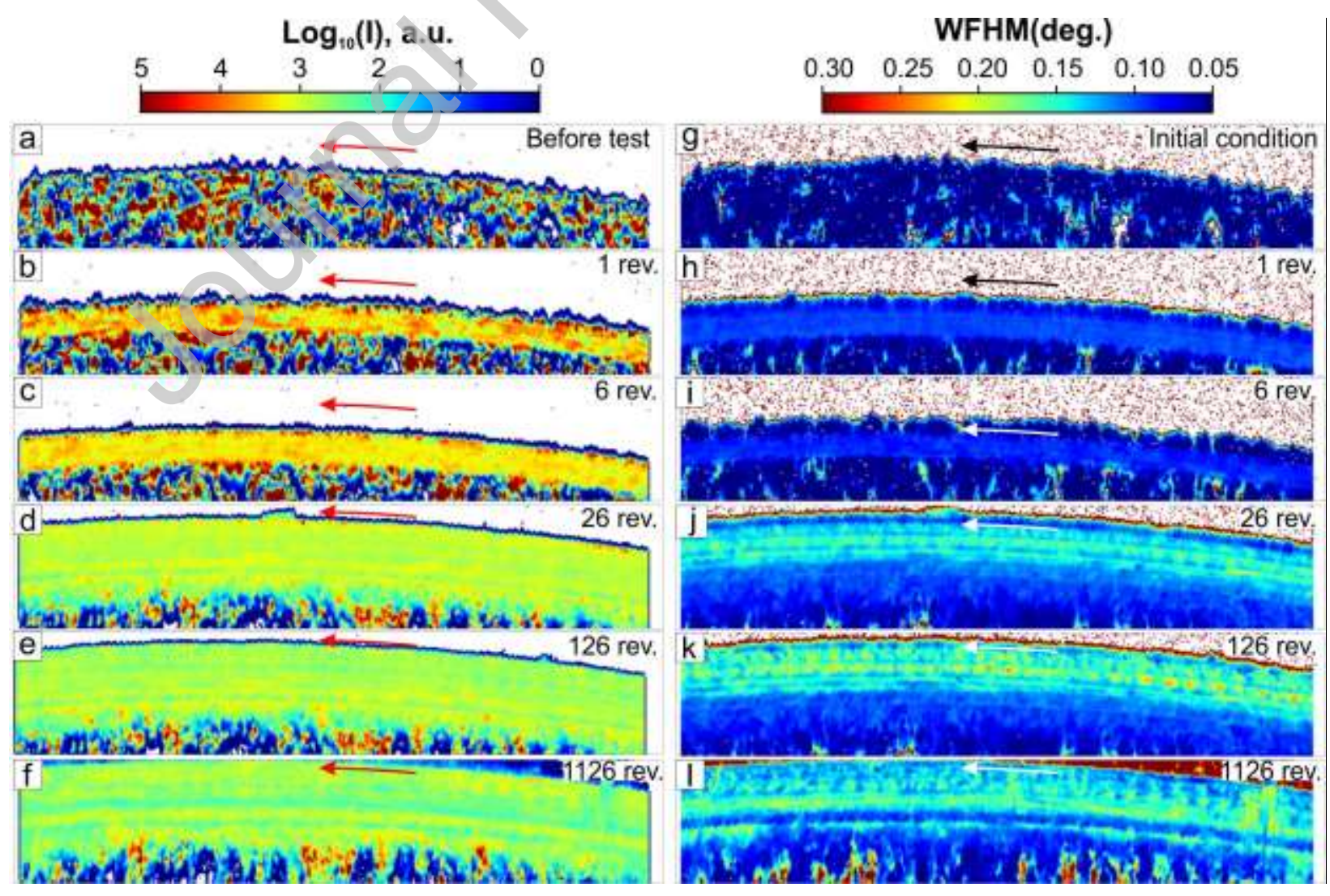


Fig. 11. Intensity (a-f) and FWHM (g-l) distributions of (112) reflection across the sample's surface after several revolutions. The arrows show the direction of sliding. During scanning, the

$\mathrm{X}$-ray beam was oriented perpendicularly to images.

\subsection{Synchrotron analyses of tribo-oxidation process}

A careful analysis of XRD patterns presented in Fig. $6 \mathrm{~b}$ revealed the presence of iron oxide peaks. In the initial condition, the oxide peak at an angle of $20.4^{\circ}$ was relatively sharp and intense. It corresponded to a thin film of iron oxide formed during the heat treatment. After the few initial revolutions, this peak gradually disappeared after 26 revolutions of the sample. During the first tens of cycles, the oxide film separates from the surface along with wear debris. The iron oxide peaks appeared again after 126 and 1126 cycles; however, they were significantly broader than those formed during the annealing. Probably, the intensive friction led to accelerated oxidation of the sample and the formation of fine-crystalline iron oxides. This process was associated with one of the varieties of tribochemical reactions, namely, tribooxidation [57, 58]. XRD analysis revealed that two types of iron oxide - hematite and magnetite - were formed (Figs. 6c and 12). It is known that at low temperatures, hematite is a stable modification of iron oxide, however, the formation of magnetite may be due to the mechanochemical reaction that occurred under friction conditions. For instance [59], the relatively short-term ball milling of hematite led to its complete transformation to magnetite. Considering the fact that mechanochemical processes inevitably accompany the friction process, it can be assumed that the hematite formed in the process of friction could transform into the magnetite.

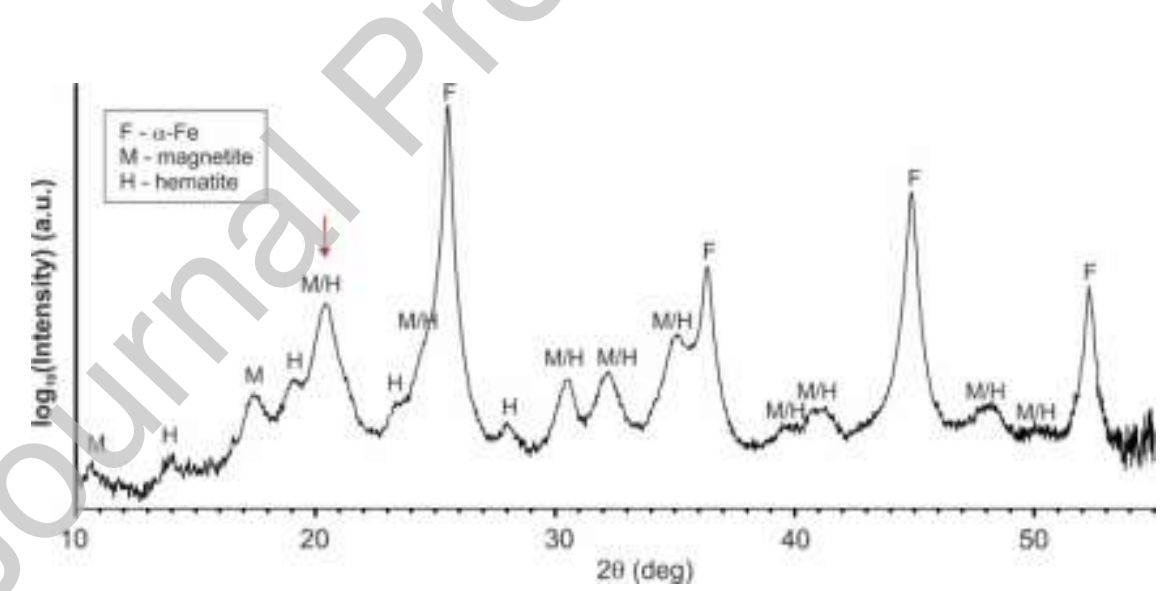

Fig. 12. XRD pattern of the samples' surface after 1126 friction cycles, demonstrating the formation of two types of iron oxide in the process of friction - hematite and magnetite. The arrow shows the positions of the peaks (110) of hematite and (311) of magnetite, the total intensity of which was used later to plot Figs. 13 and 14.

Analyzing the intensity variation of the peak at 20.5 degrees corresponding to (110) planes of hematite and (311) planes of magnetite depending on the number of revolutions (Fig. 13), one could distinguish 3 stages of the friction process. At the first stage, the material and the initial oxide film were rapidly worn out. With the friction regimes used in this work, this stage ended during the first 5-10 cycles. At the second stage, relatively slow growth of the oxideenriched layer occurred, which almost completely covered the sample surface. The progressive growth of this layer was accompanied by a gradual increase in the intensity of oxide peaks. This stage ended between 200 and 300 cycles of friction. The third stage was associated with the 
dynamic processes of formation and failure of the oxide layer, which was accompanied by corresponding oscillations in the relative intensity of the oxide peaks.

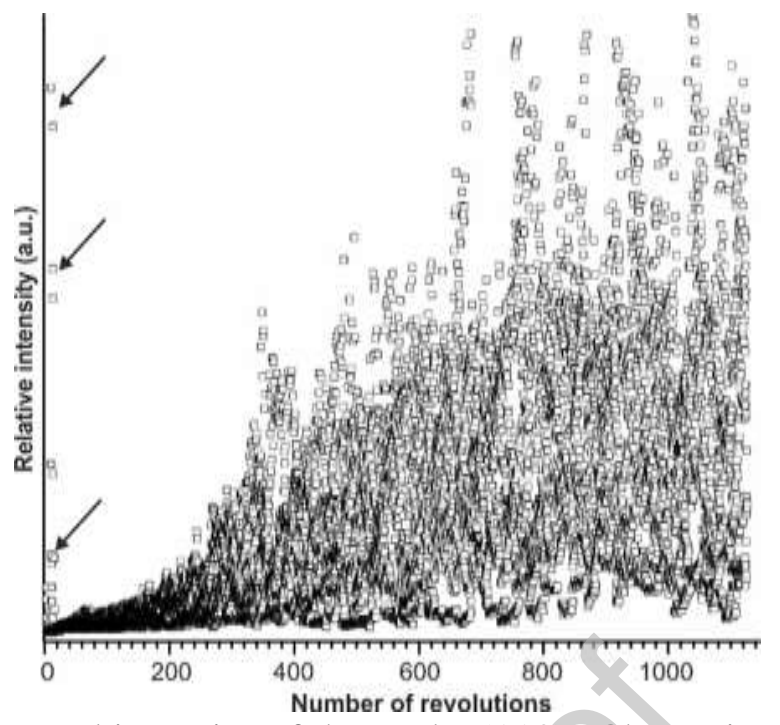

Fig. 13. Variation of the total intensity of the peaks (110) of hematite and (311) of magnetite depending on the number of revolutions. The arrows indicate the measurements obtained from an oxide film that initially presented on the sample surface.

These conclusions can be confirmed by analysis of the distribution of the oxides' peak intensities over the sample surface (Fig. 14). The nonuniform distribution of the iron oxide peaks intensity before the start of the test (Fig. 14a) was probably associated with the crystallographic misorientation of individual areas of an oxide film. Most of the original film was damaged after the first revolution (Fig. 14b). Howeyer, the traces of it were still observable after six revolutions (Fig. 14c). After 26 cycles of friction, a continuous layer containing the newly formed oxide particles started to cover the sample surface (Fig. 14d). By the $126^{\text {th }}$ cycle, the area occupied by oxides increased significantly and the intensity of the corresponding peaks increased (Fig. 14e). Subsequent frictional loading significantly increased the thickness of the oxide-containing layer, but leading to its failure (Fig. 14f, the spalling areas are shown by black arrows).

Besides the peak broadening mentioned above for $\alpha$-Fe (Fig. 5), which was related to a gradual accumulation of defects and microstructural refinement, Fig. $6 \mathrm{c}$ also shows that peaks of the $\alpha$-Fe slightly shifted to lower Bragg's angles, indicating an increase of Fe lattice parameter. It is interesting to notice that the peak shift ceases at 26 turns and re-starts after 126 revolutions. In other words, the peak shift correlates with the reduction and rise of oxidation, respectively observed in Fig. 6c. This behavior indicates that the oxygen already available in the Fe oxide interstitially diffuses into $\alpha-\mathrm{Fe}$, suggesting its consumption and competition between diffusion and oxidation, which finally reaches equilibrium when oxidation and peak shifting re-start. Despite being a good explanation, one could argue that, instead of oxygen, carbon, or even other alloying elements already present in the alloy, could diffuse into $\alpha-\mathrm{Fe}$. Also, as the tests were at room temperature, possibly activation would be absent for the diffusion. However, it must be borne in mind that oxygen possesses the highest diffusion coefficient compared to any other element in the composition [60].

Regarding temperature for diffusion activation, it became clear from the discussion of Fig. 5 that, since the initial instants, there is an enormous increase in stored energy by the increased number of defects. Of course, stored energy accumulated by defects is recovered by the microstructural refinement, which, in fact, creates more defects by the increase of boundaries. Nonetheless, as it usually happens in any mechanical working, defects are 
continually increased with further deformation even with the presence of recrystallization, hence furnishing more than enough energy for activating the diffusion process, which is also favored by the augmented surface area dictated by reduced grains sizes.
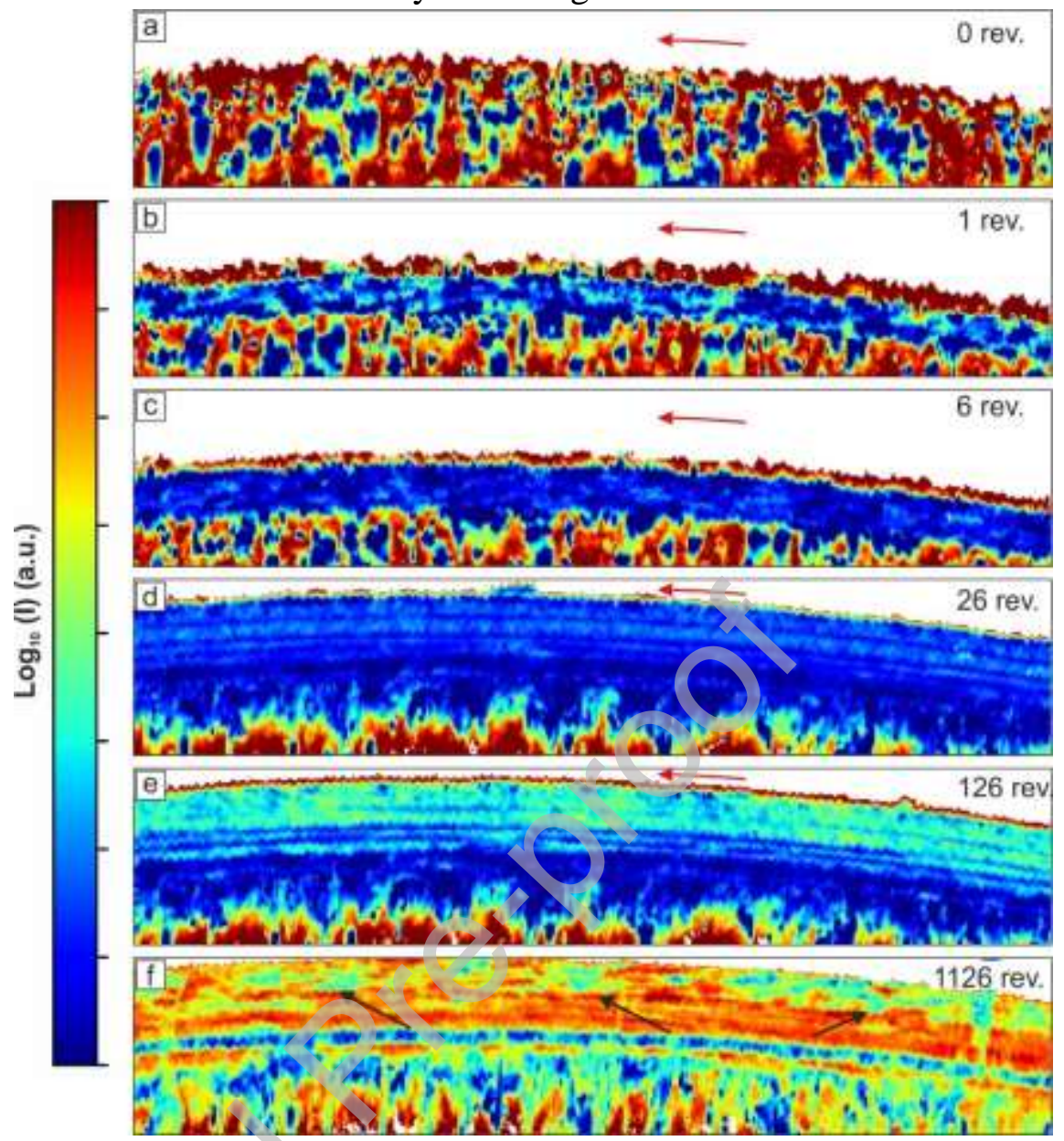

Fig. 14. Distribution of the total intensities of (110) hematite and (311) magnetite peaks over the surface of the samples after a different number of friction cycles. Arrows show the direction of sliding. During scanning, the X-ray beam was oriented perpendicularly to images.

\subsection{Ex-situ characterization of the structure and properties using complementary approaches}

Five additional samples subjected to 1, 6, 26, 126, and 1126 cycles of friction, were prepared outside the ESRF, keeping the same test conditions, and analyzed by standard metallographic ex-situ destructive methods. The cross-sections of the samples along the friction direction were ground and polished using conventional techniques. The microstructure was revealed using the nital etching solution.

The classical ex-situ characterization techniques can significantly complement the understanding of dry friction and associated phenomena.

Fig. 15 shows the surface topography of the samples. A significant effect caused by friction was observed after the $26^{\text {th }}$ cycle (Fig. 15b). The resulting deep grooves probably indicate the beginning of the process of adhesive wear, which will later be more clearly confirmed using SEM analysis of the wear surface and the wear debris. After the lengthy sliding, the surface of the sample was entirely covered by wear grooves and zones of spallation of the surface layer (Fig. 15c), which correlates well with the results of the synchrotron analysis presented in Fig. $14 \mathrm{f}$. 

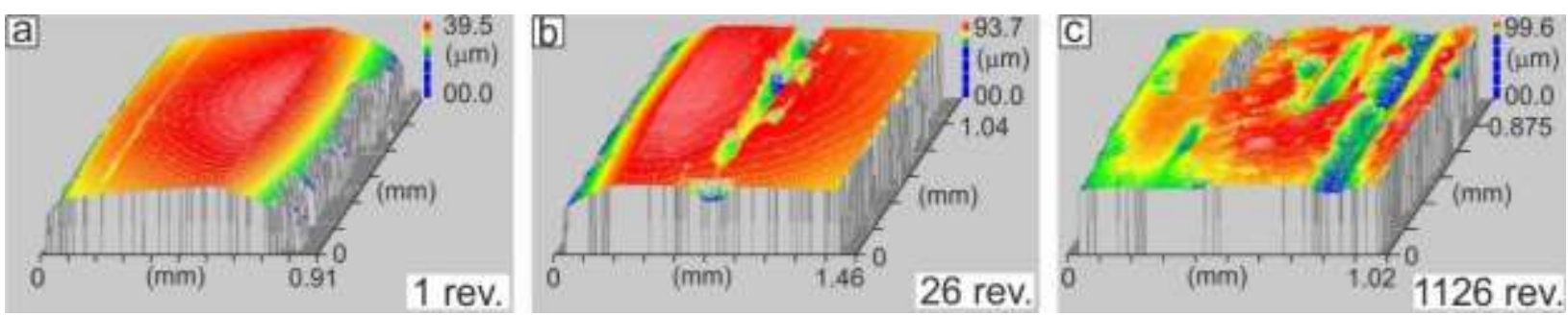

Fig. 15. An optical interferometer image of the samples' topography after the friction tests.

The results of the SEM study of the friction surface (Fig. 16) are in good agreement with this conclusion. After the first revolution of the sample (Fig. 16a), weak grooves left by the pin were formed on the surface, through which the boundaries of the initial grains were still weakly visible. After six revolutions, the number of tracks and their depth increased (Fig. 16b). After 26 revolutions, one could distinguish the areas of local adhesion, tearing of the material (Fig. 16c), which is consistent with the image in Fig. 15b. At the end of 126 cycles of friction, the traces of significant plastic deformation, elongation, spreading, and cracking of the material were observed (Fig. 16d), which was probably caused by the adhesive interaction between the sample and the indenter. After 1126 friction cycles, the surface of the sample became smoother. However, the traces of the surface layer separation were still observed on it (Fig. 16e).

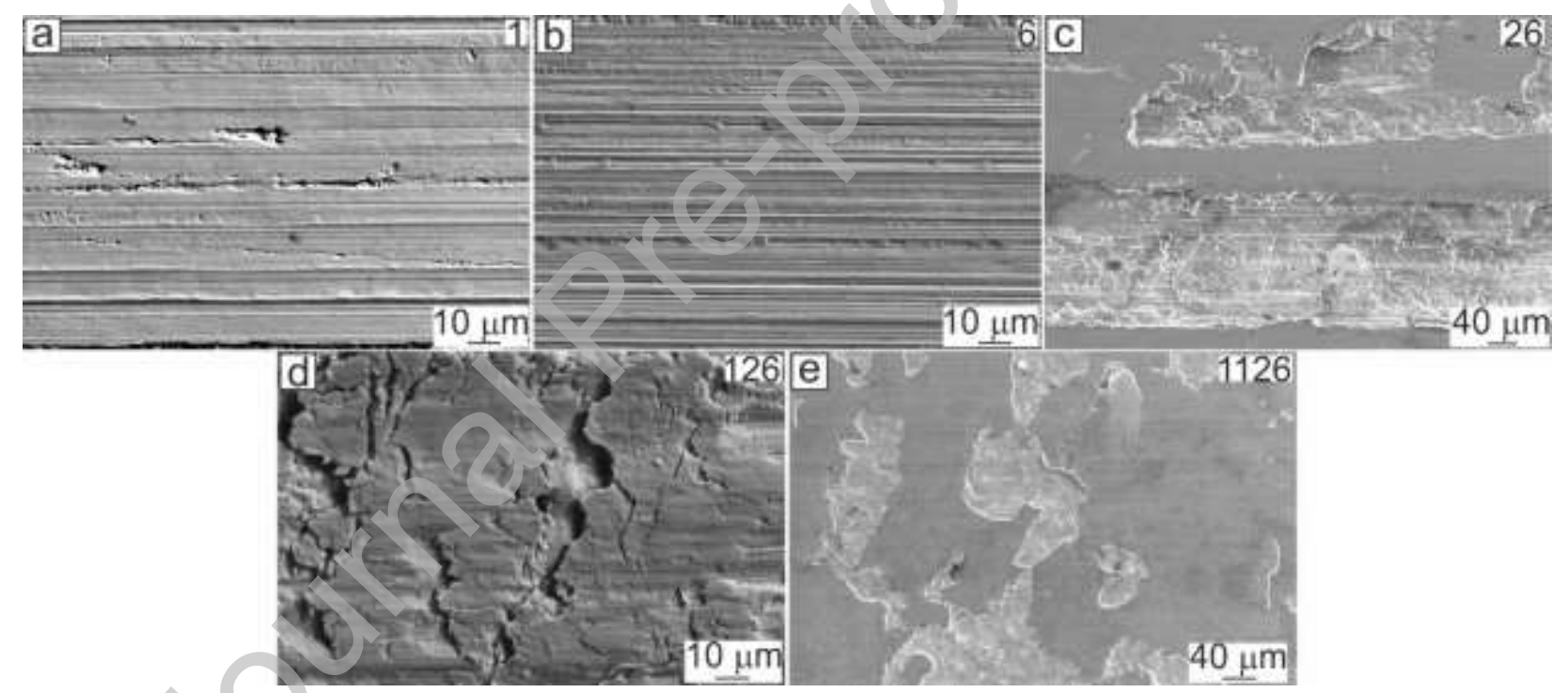

Fig. 16. SEM images of the friction surface after a different number of revolutions.

A closer look at the sample's cross-section revealed that the slight elongation of ferrite grains in the friction direction became noticeable after six revolutions of the sample (Fig. 17b). After 26 revolutions of the sample, plastic deformation became noticeably distinguishable (Fig. 17c). Ferrite grains were significantly elongated in the friction direction and narrowed in the transverse direction. A similar situation is observed for colonies of lamellar perlite. After 1126 revolutions in addition to the apparent plastic deformation, the formation of the so-called mechanically mixed layer is observed above the layer of elongated grains (Fig. 17d). This layer is composed of elements of both the sample and the pin, as well as of significant amount of oxygen. This layer is not continuous, which is probably due to its spalling or local delamination during the test. This observation is in good agreement with the images in Fig. 16e. It is interesting to note that the mechanically mixed layer merges smoothly with the deformed ferritepearlite steel structure (Fig. 17d), and it is not possible to distinguish precisely the interface between the steel and this layer based on SEM studies. 

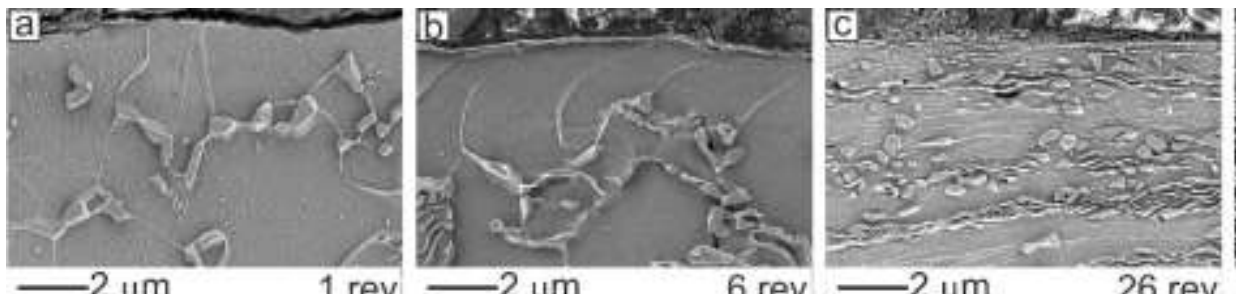

6 rev $-2 \mu \mathrm{m}$

26 rev

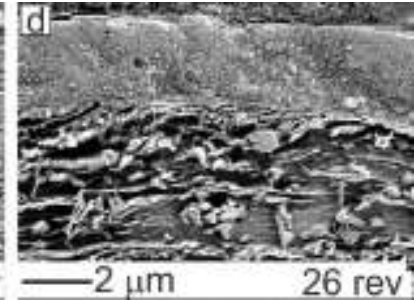

Fig. 17. The cross-section of mild steel after a different number of dry sliding friction cycles.

After 26 or more friction cycles, specific rotation of the material can be observed in some regions of the sample's surface (Fig. 18). It is accompanied by the propagation of cracks into the depths of the samples, which is probably one of the mechanisms of the surface layers' failure. This phenomenon is of great interest and will be considered in more detail in later studies.
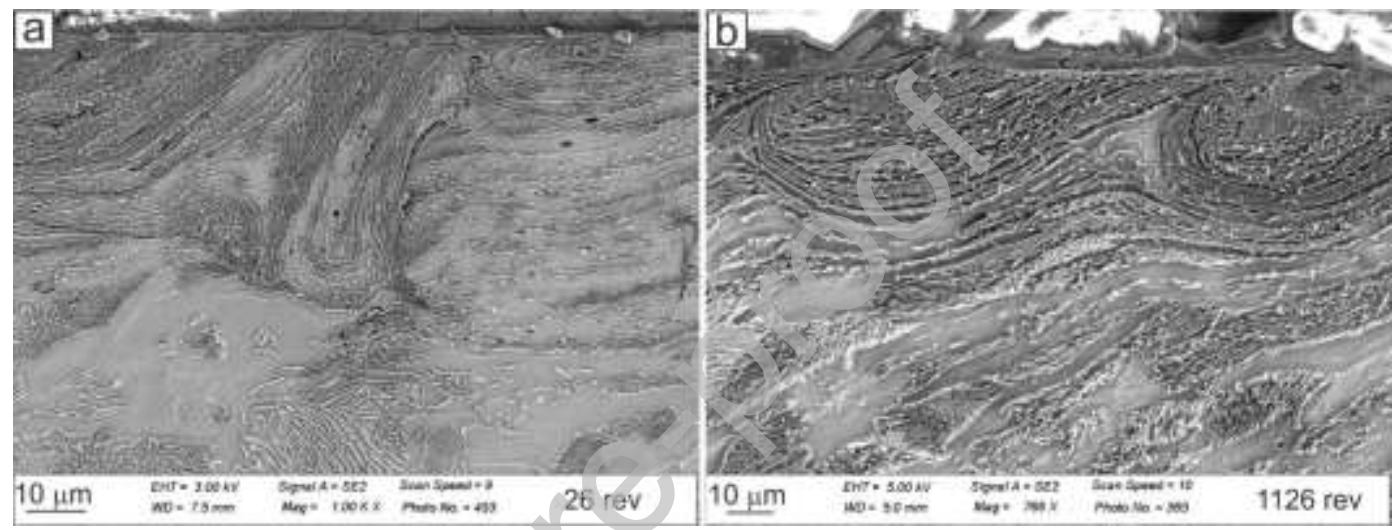

Fig. 18. Vortex-like plastic flow in the subsurface layers of mild carbon steel subjected to dry friction.

The effect of the plastic strain accumulation in the subsurface layers is well observed when analyzing the distribution of the microhardness (Fig. 19). The deformed layer cannot be observed by micro-indentation when the number of revolutions was below six, even though the structural transformations after a similar impact are undoubtedly observed using the synchrotron XRD method. At the same time, the deformed layer is clearly distinguishable on samples subjected to friction for 26, 126, and 1126 cycles. For these samples, the thickness of the deformed layer is in the range 100-150 $\mu \mathrm{m}$ (i.e., it is almost the same for all three samples). Thus, it seems that a significant deformation begins simultaneously with the initiation of the adhesive wear mechanism. 


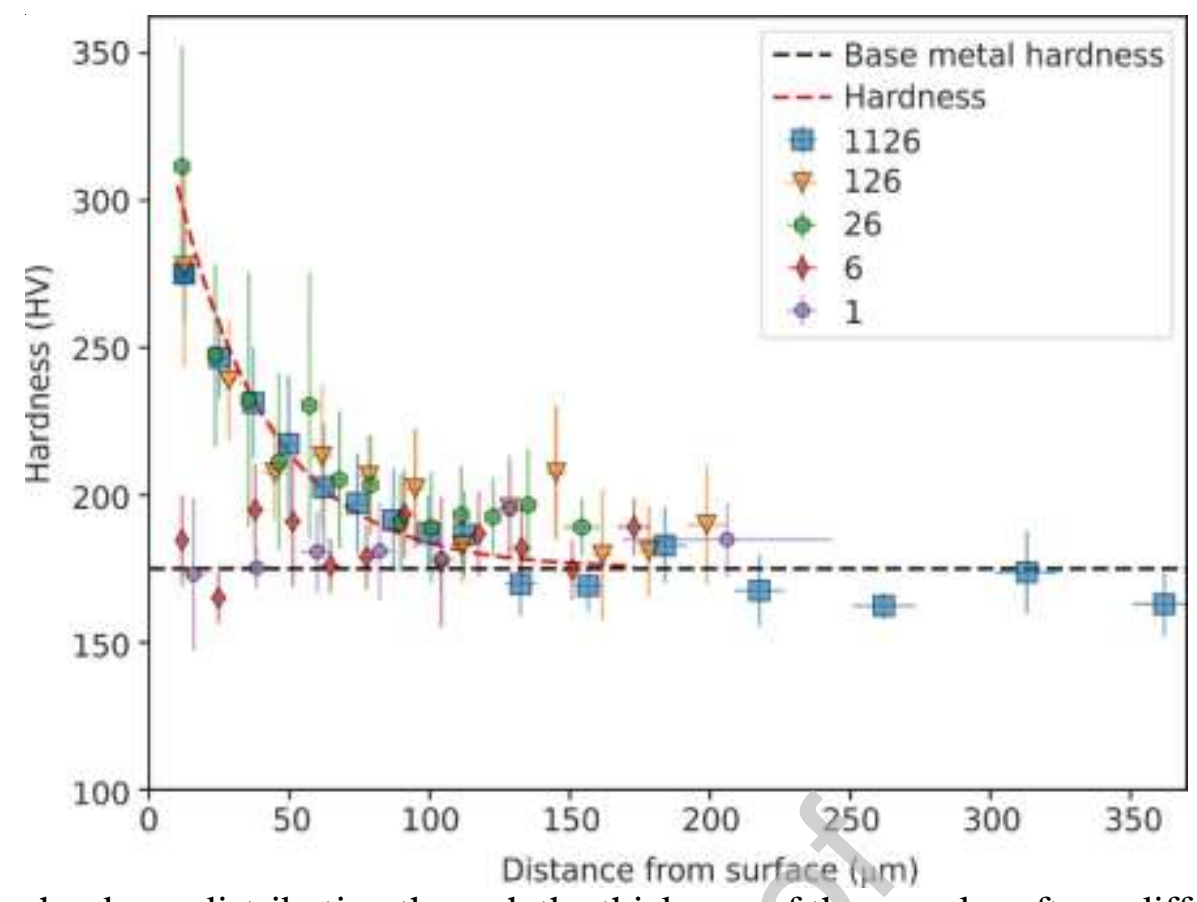

Fig. 19. Microhardness distribution through the thickness of the samples after a different number of dry sliding friction cycles.

After completion of the tests with 1126 revolutions, a shiny black film can be observed covering the surface of the sample and having the same color as the wear debris. SEM analysis of the debris (Fig. 20a) indicates that wear occurs due to peeling off relatively large flake-like particles (so-called delamination wear mechanism). Smaller particles probably appear as a result of grinding the large particles between the pin and the sample. It should be noted that, despite the significant amount of oxygen detected in the wear debris by the EDX method (Fig. 20b) and its black color, which is typical for some modifications of iron oxide, that the debris is mainly composed of $\alpha-\mathrm{Fe}$ (Fig. 20c). The absence of distinct peaks of iron oxides in the XRD pattern is probably due to their low volume fraction. This result is in agreement with the study of Lim and Ashby [57], who showed that with friction speeds of up to $1 \mathrm{~m} / \mathrm{s}$, the wear particles are predominantly metallic, and, above this speed, they are composed of oxides.
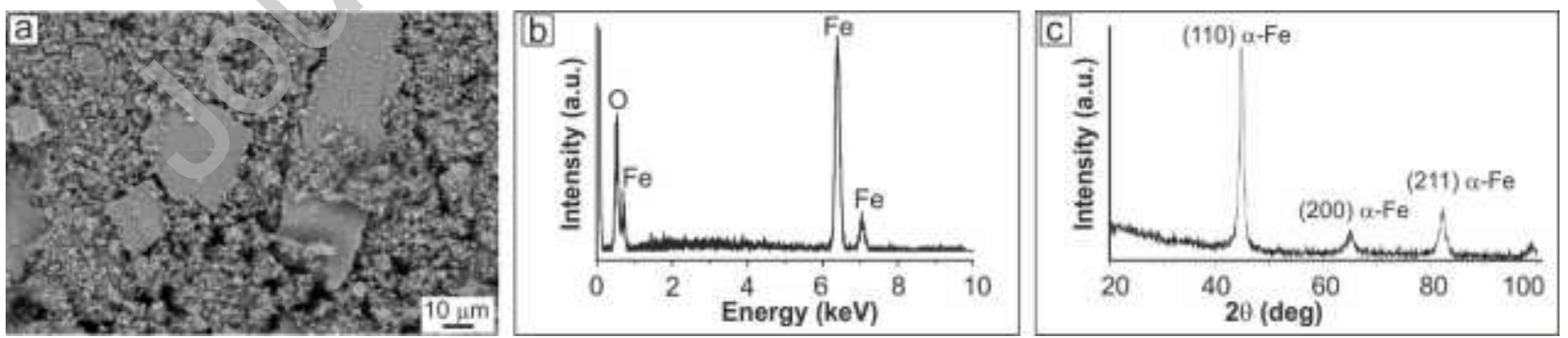

Fig. 20 (a) SEM image of wear debris collected after 1126 sample revolutions, (b) EDX spectrum confirming the presence of oxygen in wear debris, (c) the XRD pattern of wear debris

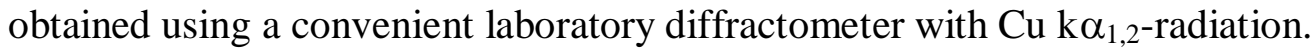

\section{Discussion}

From the results presented in the previous sections, one can conclude that the processes of wear and formation of the subsurface structure during dry sliding friction are associated with the action of two essential mechanisms: subsurface deformation and oxidation. These mechanisms, 
acting synergistically, lead to the formation of the so-called mechanically mixed layer on the sample surface. The stationary stage of wear is associated with the cyclic formation and failure of this layer.

Analyzing the process of the subsurface deformation, we can distinguish the following main stages.

1. The stage of rapid accumulation of defects: under the selected friction condition, this stage ends in about 40 cycles. This stage is accompanied by the accumulation of dislocations and the refinement of CSR. The beginning of intense adhesive interaction and the local tearing of material coincides with the completion of this stage and the achievement of a specific threshold concentration of microstructural defects. It should be noticed that refinement of the grain size may promote the adhesion between the sample and the counter-body. According to the study of Peng et al. [61], adhesion increases when the grain size decreases. They explained this observation purely due to the different mechanical responses of coarse-grained and fine-grained samples to the external load. In a review paper [62] Bhushan claimed, that the polycrystalline form of metal exhibits higher adhesion than single crystal form, which he explained by the effect of grain boundary energies. The adhesion also depends on the surface energy [62]. The surface energy of severely deformed materials is known to be higher than that of coarse-grained counterparts [63]. Besides, by reducing the grain size and introducing more dislocations, vacancies, and other defects to the surface layer, the energy stored by lattice defects greatly increases, making the material more prone to chemical interaction with counter-body. Finally, with the reduction of the grain size, the surface of the grain, interacting with the counter-body becomes comparable with the total grain surface. This should increase the adhesive/cohesive ratio per grain, making fine-grained materials more susceptible to adhesion.

2. The stage when the maximum concentration of defects is reached and the fluctuations around a certain average value of defects starts. Several factors limit the threshold concentration of defects. First, at the later stages of plastic deformation, a specific equilibrium state is established between the processes of nucleation and annihilation of dislocations when further dissipation of the deformation energy due to the accumulation of new defects becomes virtually impossible. Secondly, a defective surface layer can dissipate energy due to its failure, i.e., due to the formation of wear debris. Thus, even if a more defective state of the material is potentially possible, it is not achieved, since the material is separated before it is reached. The oscillation behavior of FWHM observed in Fig. 7a is related to a combination of the flowing mechanisms. First, each point of the sample's surface is at its own stage of the microstructural evolution, and this stage may be different for different parts of the sample. Second, the oscillation may be associated with the formation of a defect-rich surface layer and its gradual separation. In this case, deeper and not yet as much deformed layers of the material lay open, and the damaging process resumes.

3. The gradual evolution of the subsurface layer structure is associated with an increase in the fraction of screw dislocations: when the threshold concentration of defects is reached, further plastic deformation occurs not due to the slip of dislocations, but due to the collective, possibly rotational, movement of many separate mesovolumes of the material as it was postulated by Panin et al. [9]. This process probably requires a change in the type of dislocation substructure. It can be assumed that at this stage, the formation of twist boundaries in the iron-based alloy is more desirable than the formation of tilt boundaries. Thus, screw dislocations begin to dominate the edge ones. 
4. The stationary stage of the wear process: at a particular stage of the sliding, further energy dissipation due to the accumulation of defects or collective motion of mesovolumes becomes impossible, and the only mechanism of energy dissipation is the failure.

In a sense, the evolution of the structure and the observed staging during friction coincide with the evolution of the structure for other types of plastic deformation. A similar conclusion was previously done in the study of Panin et al. [9]. It is interesting to note that Panin et al. considered the motion of a nanostructured layer during sliding friction as the motion of a viscous paste in which a fluid-like binder bonds solid particles.

Nevertheless, it should be noted that the direct analogy between the staged evolution of the structure during macroscopic plastic deformation and friction is not entirely correct since the friction process is more complicated because of tribochemical reactions: interaction with the counter body, oxidation, the formation of wear debris and the involvement of the entire set of these phenomena in the formation of the mechanically mixed layer.

It makes sense to consider in more detail the issue of changing the dislocations type during the friction process (Fig. 9) as this was poorly covered in the previous studies devoted to friction. Zehetbauer and Seumer [64] showed that with the implementation of many different schemes of materials plastic deformation, the evolution of their dislocation structure is the same. At the initial stages of deformation, the active accumulation of both screw and edge dislocations begins. However, at the final stages preceding the failure, various mechanisms of dislocations annihilation are activated because with an increase in the dislocation density, the probability of meeting and annihilation of dislocations of opposite signs increases. The annihilation of screw dislocations is associated with the cross-slip phenomena and annihilation of edge ones with the climb phenomena. The dominance of one or another type of dislocations in the final structure depends on which process - the climb or the cross-slip - occurs easier. It should also be added that the predominance of the screw or edge dislocations at the final stages of the deformation process is probably associated not only with the issue of the dominating annihilation mechanism but also with the issue of the simplicity of nucleation of one or another dislocation type in a finecrystalline structure saturated with defects.

Combining the data of Fig. 9 and 10, it can be noted that at the initial stages of friction (up to 50 cycles), the density of both edge and screw dislocations increases, but the rates of these processes differ significantly. Up to 50 revolutions, the rate of edge dislocations nucleation increases, while the rate of screw dislocations nucleation decreases. Probably, due to significant differences in the energy of the Peierls barrier, the edge dislocations in bcc metals are more mobile than screw dislocations. As a result, the initial stages of deformation in such materials occur through the movement of edge dislocations.

At the subsequent stages of cyclical frictional loading (50 - 600 revolutions), a gradual increase in the fraction of screw dislocations and a corresponding decrease of the fraction of the edge ones occurs. This fact deserves attention since, in the case of severe plastic deformation of many fcc metals, the opposite situation is observed - the prevalence of the edge dislocations in the final material $[65,66]$. This phenomenon can be explained if one takes into account the peculiarities of the core structure of screw dislocations in bec metal. Most of the simulationbased studies predict that splitting of screw dislocations in bcc alloys leads to the formation of a non-planar configuration of the core [67]. At the same time, the core of edge dislocation in bcc metals is planar. Such a planar core explains much higher mobility of edge dislocations in comparison to that of screw dislocations in bcc iron. Due to the low mobility of screw dislocations, their annihilation at the later stages of plastic deformation occurs much harder, probably explaining the observed domination of screw dislocations in the current experiment. 
Along with the increase in the density of screw dislocations, the active annihilation of the edge dislocations occurs, indicating that at these stages of deformation, not only slip but also climb processes are activated. Several factors may be responsible for this. Firstly, active plastic deformation leads to the formation of a significant number of vacancies which facilitate the climb of edge dislocations. Secondly, the presence of stress concentrators can lead to the formation of edge dislocation loops located in parallel slip systems. The convergence of parts of such loops to several interatomic distances can lead to their annihilation due to their climb. All these mechanisms are well studied and described in detail in the literature [68].

It should be noted that an increase in the fraction of screw dislocations in severely deformed bcc iron was previously reported by Forouzanmehr et al. [53], Bargujer et al. [69], Nasab et al. [70].

By considering chemical reactions, three main stages of friction can be distinguished:

1. The destruction of the initial oxide film: under the friction regimes used in this study, this stage is completed during the first few cycles of the interaction of the pin and the sample.

2. The beginning of the adhesive interaction, leading to a gradual formation of the mechanically mixed layer. After the initial oxide film is destroyed, nothing prevents the pin and the sample from the adhesive interaction, which leads to the rapid degradation of the surface layers and the development of the wear process. The adhesion is probably facilitated by mechanical activation of the sample surface due to its severe plastic deformation and the corresponding accumulation of defects. The mechanical activation of the surface, as well as the temperature increase caused by friction, facilitates oxidation. In the process of severe plastic deformation, a relatively brittle oxide film is cyclically destroyed and mechanically mixes with the defective layers of steel located beneath it. In this process, a so-called mechanically mixed layer was formed. In this case, the process of mechanical mixing is enhanced due to the specific rotation of the microvolumes of the subsurface layer (see Fig. 18), It should be noted that, in this case, the material of the pin is practically absent in the mechanically mixed layer and the wear debris. Such an absence is because the WC-Co pin had significantly higher hardness than the material of the sample. Besides, it also weakly interacts with steel due to the high chemical stability of tungsten carbide. Thus, almost the entire mechanically mixed layer consists of the material of the steel, as well as of iron oxides. The similarity of the processes of mechanochemical reactions occurring during dry sliding friction and mechanical alloying in ball mills has already been noted in several studies, for example, in Rigney et al. [16]. From the metallographic study, it follows that the thickness of the layer of mechanical mixing reached 2-4 $\mu \mathrm{m}$.

3. The destruction of the mechanically mixed layer. Upon reaching the critical thickness and defectiveness, the mechanically mixed layer exfoliates and exposes the relatively low-defect and non-oxidized layers of steel. The exfoliated particles are either removed from the surface of the sample or fall into the contact zone between the sample and the pin, mechanically mixing with the existing surface layer, or contributing to its plastic deformation due to abrasion. At the stationary stage of friction, this process is periodically repeated.

\section{Conclusions}

The approach used in this study, which is based on operando and ex-situ diffraction analysis of the friction surface using synchrotron radiation, is in good agreement with the results obtained using classical metallographic methods. By applying this approach to different types of friction pairs and friction regimes, it is possible to significantly supplement the existing ideas about the processes that occur during wear. In comparison with classical ex-situ methods to study the microstructural evolution caused by friction, this approach allows one to reduce the 
number of experiments (only one experimental sample is needed per each friction regime), reduce the experimental time, increase the number of data points (in this study 10 data points were used for each cycle of friction with the duration of $1 \mathrm{~s}$; besides, modern $2 \mathrm{~d}$ detectors have a much higher acquisition rate) and retrieve a large number of structural parameters from a single experiment. Thus, the total cost of experiments can be reduced. Currently, the application of the designed device is possible only with highly brilliant X-ray sources. This can be considered as the limitation of the approach. Some studies on the wear processes of other materials will be presented in the following up publications.

Based on the results of this study, the following conclusions can be drawn.

1. The process of wear during the friction of carbon steel against the WC-Co pin occurred due to the cooperative action of plastic deformation and oxidation.

2. The process of plastic deformation in subsurface layers began to develop during the first cycle of frictional interaction. This process was manifested in increasing the dislocation density, refinement of CSR, and gradual change of the dislocation type. The number of defects quickly reached a threshold value and subsequently fluctuated near it due to periodically repeated processes of defect accumulation and stress relaxation due to material wear.

3. The friction conditions used in this study led to the quick formation of a mechanically mixed layer, consisting of the sample material and a mixture of two types of iron oxide hematite and magnetite. The delamination of this layer was probably the primary wear mechanism.

\section{Declaration of Competing Interest}

The authors declare that they have no known competing financial interests or personal relationships that could have appeared to influence the work reported in this paper.

\section{Acknowledgements}

The microscopy research was carried out using equipment of the center "Materials structure and properties" in Novosibirsk State Technical University

\section{Funding}

This study was funded according to Federal Task of The Ministry of Science and Higher Education of the Russian Federation (\#2019-0931 "Characterization of metastable structures, formed at surfaces and interfaces due to extreme external impacts”)

\section{References}

[1] H.P. Jost, The economic importance of tribology in the conservation of energy, Tribologie Reibung . Verschleiß. Schmierung, Springer1981, pp. 9-38.

[2] B. Bhushan, Tribology: Friction, Wear, and Lubrication, in: R.C. Dorf (Ed.), The Engineering Handbook, 2nd Edition, CRC Press, Florida, 2004.

[3] K. Kato, K. Adachi, Wear Mechanisms, in: B. Bhushan (Ed.), Modern tribology handbook, Volume One, Principles of Tribology, CRC press2000, pp. 273-300.

[4] G.W. Stachowiak, Wear: materials, mechanisms and practice, John Wiley \& Sons 2006.

[5] D.A. Rigney, Transfer, mixing and associated chemical and mechanical processes during the sliding of ductile materials, Wear. 245(1-2) (2000) 1-9.

[6] D. Tabor, Friction - the present state of our understanding, J. Lubr. Technol. 103(2) (1981) 169-179. 
[7] P. Heilmann, D.A. Rigney, An energy-based model of friction and its application to coated systems, Wear. 72(2) (1981) 195-217.

[8] D. Rigney, Sliding wear of metals, Annu. Rev. Mater. Sci. 18(1) (1988) 141-163.

[9] V. Panin, A. Kolubaev, S. Tarasov, V. Popov, Subsurface layer formation during sliding friction, Wear. 249(10-11) (2001) 860-867.

[10] C. Greiner, J. Gagel, P. Gumbsch, Solids Under Extreme Shear: Friction-Mediated Subsurface Structural Transformations, Adv. Mater. 31(26) (2019).

[11] X. Wang, X. Wei, X. Hong, J. Yang, W. Wang, Formation of sliding friction-induced deformation layer with nanocrystalline structure in T10 steel against 20CrMnTi steel, Appl. Surf. Sci. 280 (2013) 381-387.

[12] A. Mahato, Y. Guo, H. Yeung, S. Chandrasekar, Surface flow in severe plastic deformation of metals by sliding, IOP Conference Series: Materials Science and Engineering, 2014.

[13] S. Alexandrov, L. Šidjanin, D. Vilotić, D. Movrin, L. Lang, Generation of a layer of severe plastic deformation near friction surfaces in upsetting of steel specimens, Metals. 8(1) (2018).

[14] A. Kapoor, F.J. Franklin, Tribological layers and the wear of ductile materials, Wear. 245(1-2) (2000) 204-215.

[15] D.A. Rigney, S. Karthikeyan, The evolution of tribomaterial during sliding: A brief introduction, Tribol. Lett. 39(1) (2010) 3-7.

[16] D.A. Rigney, L.H. Chen, M.G.S. Naylor, A.R. Rosenfield, Wear processes in sliding systems, Wear. 100(1-3) (1984) 195-219.

[17] S.L. Rice, H. Nowotny, S.F. Wayne, Characteristics of metallic subsurface zones in sliding and impact wear, Wear. 74(1) (1981) 131-142.

[18] D.A. Rigney, Comments on the sliding wear of metals, Tribology International 30(5) (1997) 361-367.

[19] G.I. Finch, A.G. Quarrell, The beilby layer, Nature. 137(3465) (1936) 516-519.

[20] A. Pyzalla, L. Wang, E. Wild, T. Wroblewski, Changes in microstructure, texture and residual stresses on the surface of a rail resulting from friction and wear, Wear. 250-251 (2001) 901-907.

[21] H. Chen, C. Zhang, W. Liu, Q. Li, H. Chen, Z. Yang, Y. Weng, Microstructure evolution of a hypereutectoid pearlite steel under rolling-sliding contact loading, Mater. Sci. Eng. A 655 (2016) 50-59.

[22] X. Wang, X. Wei, J. Zhang, R. Li, M. Hua, W. Wang, Formation of Nanocrystallized Structure in Worn Surface Layer of T10 Steel against 20CrMnTi Steel during Dry Rubbing, J. Nanomater. 2016 (2016).

[23] R. Pan, R. Ren, C. Chen, X. Zhao, Formation of nanocrystalline structure in pearlitic steels by dry sliding wear, Mater. Charact. 132 (2017) 397-404.

[24] W. Österle, H. Rooch, A. Pyzalla, L. Wang, Investigation of white etching layers on rails by optical microscopy, electron microscopy, X-ray and synchroton X-ray diffraction, Mater. Sci. Eng. A 303(1-2) (2001) 150-157.

[25] D.R. Wheeler, D.H. Buckley, Texturing in metals as a result of sliding, Wear. 33(1) (1975).

[26] V. Scott, H. Wilman, Surface re-orientation caused on metals by abrasion-its nature, origin and relation to friction and wear, Proc. R. Soc. Lond. A. Math. Phys. Sci. 247(1250) (1958) 353-368.

[27] N.P. Suh, An overview of the delamination theory of wear, Wear. 44(1) (1977) 1-16.

[28] S. Becker, U. Popp, C. Greiner, A reciprocating optical in situ tribometer with high-speed data acquisition, Rev. Sci. Instrum. 87(8) (2016).

[29] K. Yagi, Y. Ebisu, J. Sugimura, S. Kajita, T. Ohmori, A. Suzuki, In situ observation of wear process before and during scuffing in sliding contact, Tribol. Lett. 43(3) (2011) 361-368.

[30] K. Yagi, N. Ikeda, J. Sugimura, S. Kajita, T. Ohmori, T. Shinyoshi, A. Suzuki, Direct observation of surface transition during scuffing in dry condition, American Society of Mechanical Engineers, Tribology Division, TRIB, 2012, pp. 305-307.

[31] M. Miyajima, K. Kitamura, K. Matsumoto, In Situ Raman Tribometry for the Formation and Removal Behavior of FeS2 Tribofilm in the Scuffing Process, Tribol. Int. 11(2) (2016) 382-388.

[32] T.W. Scharf, I.L. Singer, Monitoring transfer films and friction instabilities with in situ Raman tribometry, Tribol. Lett. 14(1) (2003) 3-8.

[33] A.I. Bennett, K.G. Rowe, W. Gregory Sawyer, Dynamic in situ measurements of frictional heating on an isolated surface protrusion, Tribol. Lett. 55(1) (2014) 205-210.

[34] Y. Matsuzaki, K. Yagi, J. Sugimura, In-situ fast and long observation system for friction surfaces during scuffing of steel, Wear. 386-387 (2017) 165-172. 
[35] Y. Liao, L. Marks, In situ single asperity wear at the nanometre scale, Int. Mater. Rev. 62(2) (2017) 99-115.

[36] T. Sato, T. Ishida, L. Jalabert, H. Fujita, Real-time transmission electron microscope observation of nanofriction at a single Ag asperity, Nanotechnology. 23(50) (2012).

[37] A.P. Merkle, A. Erdemir, O.L. Eryilmaz, J.A. Johnson, L.D. Marks, In situ TEM studies of tribo-induced bonding modifications in near-frictionless carbon films, Carbon. 48(3) (2010) 587-591.

[38] A.P. Merkle, L.D. Marks, Liquid-like tribology of gold studied by in situ TEM, Wear. 265(11-12) (2008) 1864-1869.

[39] Y. Liao, E. Hoffman, L.D. Marks, Nanoscale abrasive wear of CoCrMo in in situ TEM sliding, Tribol. Lett. 57(3) (2015).

[40] K. Anantheshwara, K. Arul Selvan, R.K. Mishra, M.S. Bobji, In situ transmission electron microscopy study of deformation of an aluminum alloy tribolayer, Scripta Mater. 60(8) (2009) 623-626.

[41] A.A. Bataev, V.G. Burov, A.A. Nikulina, I.A. Bataev, D.V. Lazurenko, A.I. Popelukh, D.A. Ivanov, A novel device for quasi in situ studies of materials microstructure during friction, Mater. Perform. Charact. 7(3) (2018).

[42] I.A. Bataev, A.A. Bataev, D.V. Lazurenko, V.G. Burov, A.I. Smirnov, A.A. Nikulina, D.A. Ivanov, Synchrotron Radiation in Analysis of Structural Transformations Under Friction Conditions of Carbon Steel, Russ. Phys. J. 61(3) (2018) 503-508.

[43] S. Kajita, K. Yagi, T. Izumi, J. Koyamachi, M. Tohyama, K. Saito, J. Sugimura, In situ x-ray diffraction study of phase transformation of steel in scuffing process, Tribol. Lett. 57(2) (2015) 1-11.

[44] K. Yagi, S. Kajita, T. Izumi, J. Koyamachi, M. Tohyama, K. Saito, J. Sugimura, Simultaneous Synchrotron X-ray Diffraction, Near-Infrared, and Visible in Situ Observation of Scuffing Process of Steel in Sliding Contact, Tribol. Lett. 61(2) (2016).

[45] B.B. He, Two-dimensional X-ray diffraction, Wiley, New Jercsey, 2009.

[46] B. Cullity, S. Stock, Elements of X-ray Diffraction, Prentice-Hall, New York, 2001.

[47] J.H. Hubbell, S.M. Seltzer, Tables of $x$-ray mass attenuation coefficients and mass energy-absorption coefficients $1 \mathrm{keV}$ to $20 \mathrm{meV}$ for elements $\mathrm{z}=1$ to 92 and 48 additional substances of dosimetric interest, National Inst. of Standards and Technology, Gaithersburg, 1996.

[48] U.R. Evans, H.A. Miley, Measurements of oxide films on copper and iron [2], Nature. 139(3511) (1937) 283.

[49] G. Ashiotis, A. Deschildre, Z. Nawaz, J.P. Wright, D. Karkoulis, F.E. Picca, J. Kieffer, The fast azimuthal integration Python library: PyFAl, J. Appl. Crystallogr. 48 (2015) 510-519.

[50] G.K. Williamson, W.H. Hall, X-ray line broadening from filed aluminium and wolfram, Acta Metall. 1(1) (1953) 22-31.

[51] T. Ungár, I. Dragomir, Á. Révész, A. Borbély, The contrast factors of dislocations in cubic crystals: The dislocation model of strain anisotropy in practice, J. Appl. Crystallogr. 32(5) (1999) 992-1002.

[52] T. Ungár, A. Borbély, The effect of dislocation contrast on x-ray line broadening: A new approach to line profile analysis, Appl. Phys. Lett. 69(21) (1996) 3173-3175.

[53] N. Forouzanmehr, M. Nili-Ahmadabadi, M. Bönisch, The analysis of severely deformed pure Fe structure aided by X-ray diffraction profile, Phys. Met. Metallogr. 117(6) (2016) 624-633.

[54] R.A. Renzetti, H.R.Z. Sandim, R.E. Bolmaro, P.A. Suzuki, A. Möslang, X-ray evaluation of dislocation density in ODS-Eurofer steel, Mater. Sci. Eng. A 534 (2012) 142-146.

[55] Y.Z. Chen, G. Csiszár, J. Cizek, S. Westerkamp, C. Borchers, T. Ungár, S. Goto, F. Liu, R. Kirchheim, Defects in carbon-rich ferrite of cold-drawn pearlitic steel wires, Metall. Mater. Trans. A Phys. Metall. Mater. Sci. 44(8) (2013) 3882-3889.

[56] M. Kumagai, M. Imafuku, S.I. Ohya, Microstructural features of cold-rolled carbon steel evaluated by X-ray diffraction line profile analysis and their correlation with mechanical properties, ISIJ Int. 54(1) (2014) 206-211.

[57] S.C. Lim, M.F. Ashby, WEAR-MECHANISM MAPS, Acta Metall. 35(1) (1987) 1-24.

[58] S.Q. Wang, M.X. Wei, F. Wang, X.H. Cui, C. Dong, Transition of mild wear to severe wear in oxidative wear of H21 steel, Tribol. Lett. 32(2) (2008) 67-72. 
[59] J.D. Betancur, J. Restrepo, C.A. Palacio, A.L. Morales, J. Mazo-Zuluaga, J.J. Fernández, O. Pérez, J.F. Valderruten, A. Bohórquez, Thermally Driven and Ball-Milled Hematite to Magnetite Transformation, Hyperfine Interact. 148-149(1-4) (2003) 163-175.

[60] T. Heumann, Diffusion in Metallen: Grundlagen, Theorie, Vorgänge in Reinmetallen und Legierungen, Springer-Verlag2013.

[61] L.F. Peng, M.Y. Mao, M.W. Fu, X.M. Lai, Effect of grain size on the adhesive and ploughing friction behaviours of polycrystalline metals in forming process, International Journal of Mechanical Sciences 117 (2016) 197-209.

[62] B. Bhushan, Adhesion and stiction: mechanisms, measurement techniques, and methods for reduction, Journal of Vacuum Science \& Technology B: Microelectronics and Nanometer Structures Processing, Measurement, and Phenomena 21(6) (2003) 2262-2296.

[63] S. Bindu, K. Sanosh, K. Smetana, A. Balakrishnan, T. Kim, An in vivo evaluation of ultra-fine grained titanium implants, Journal of materials science \& technology 25(4) (2009) 556.

[64] M. Zehetbauer, V. Seumer, Cold work hardening in stages IV and V of F.C.C. metals-I. Experiments and interpretation, Acta Metall. Mater. 41(2) (1993) 577-588.

[65] E. Schafler, M. Zehetbauer, T. Ungàr, Measurement of screw and edge dislocation density by means of X-ray Bragg profile analysis, Mater. Sci. Eng. A 319-321 (2001) 220-223.

[66] D. Fátay, E. Bastarash, K. Nyilas, S. Dobatkin, J. Gubicza, T. Ungár, X-ray diffraction study on the microstructure of an Al-Mg-Sc-Zr alloy deformed by high-pressure torșion, Z. Metallkd. 94(7) (2003) 842847.

[67] C.R. Weinberger, B.L. Boyce, C.C. Battaile, Slip planes in bcc transition metals, Int. Mater. Rev. 58(5) (2013) 296-314.

[68] J. Friedel, Dislocations: International Series of Monographs on Solid State Physics, Elsevier2013.

[69] S.S. Bargujer, N.M. Suri, R.M. Belokar, X-ray diffraction analysis of severely cold deformed hypereutectoid steel wire, Def. Sci. J. 65(6) (2015) 500-507.

[70] F. Hosseini Nasab, S. Hossein Nedjad, S. Karimi, A comparison between the dislocation structure of ball-milled iron and copper as derived from the X-ray diffraction peak profile analyses, Phys. Met. Metallogr. 114(12) (2013) 1069-1073. 


\section{Graphical abstract}

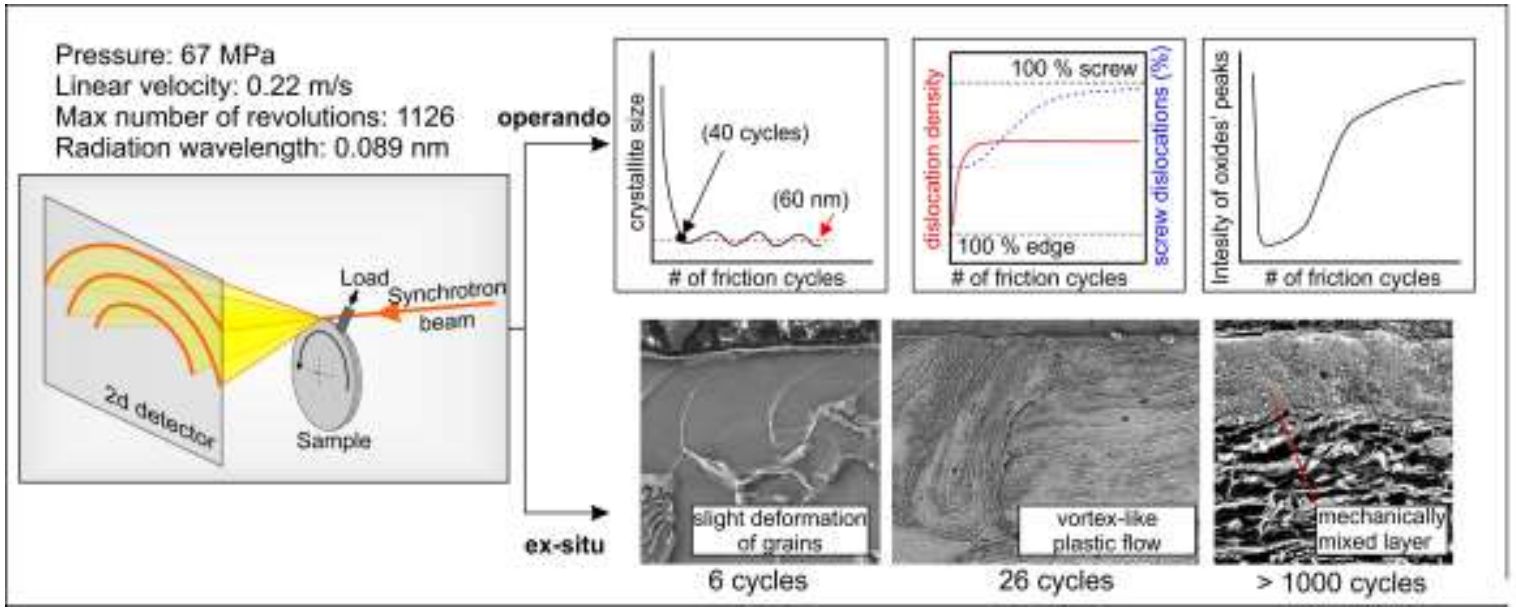

